\title{
Investigating (Pseudo)-Heterogeneous Pd-Catalysts for Kraft Lignin Depolymerization under Mild Aqueous Basic Conditions
}

\author{
Dolorès Bourbiaux ${ }^{1}$, Yu Xu ${ }^{2} \mathbb{D}$, Laurence Burel ${ }^{1}$, Firat Goc ${ }^{1}$, Pascal Fongarland ${ }^{3} \mathbb{D}$, Régis Philippe ${ }^{3} \mathbb{D}$, \\ Guillaume Aubert ${ }^{2}$, Cyril Aymonier ${ }^{2}$ (D), Franck Rataboul 1,* and Laurent Djakovitch 1,*(D)
}

1 CNRS, IRCELYON, Université de Lyon, Université Claude Bernard Lyon 1, UMR 5256, 2 Avenue Albert Einstein, CEDEX, 69626 Villeurbanne, France; dbb@lgpc.cpe.fr (D.B.);

laurence.burel@ircelyon.univ-lyon1.fr (L.B.); firat.goc@ircelyon.univ-lyon1.fr (F.G.)

2 CNRS, Bordeaux INP, ICMCB, Université de Bordeaux, UMR 5026, 87 Avenue du Docteur Schweitzer, CEDEX, 33600 Pessac, France; yu.xu@icmcb.cnrs.fr (Y.X.); guillaume.aubert@icmcb.cnrs.fr (G.A.); cyril.aymonier@icmcb.cnrs.fr (C.A.)

3 CNRS, CPE-Lyon, CP2M, Université de Lyon, Université Claude Bernard Lyon 1, UMR 5128, 43 Boulevard du 11 Novembre 1918, CEDEX, 69616 Villeurbanne, France; pfo@lgpc.cpe.fr (P.F.); rph@lgpc.cpe.fr (R.P.)

* Correspondence: franck.rataboul@ircelyon.univ-lyon1.fr (F.R.); laurent.djakovitch@ircelyon.univ-lyon1.fr (L.D.)

Citation: Bourbiaux, D.; Xu, Y.; Burel, L.; Goc, F.; Fongarland, P.; Philippe,

R.; Aubert, G.; Aymonier, C.;

Rataboul, F.; Djakovitch, L.

Investigating (Pseudo)-Heterogeneous

Pd-Catalysts for Kraft Lignin

Depolymerization under Mild Aqueous Basic Conditions. Catalysts 2021, 11, 1311. https://doi.org/ $10.3390 /$ catal11111311

Academic Editor: Anna Maria Raspolli Galletti

Received: 28 September 2021

Accepted: 21 October 2021

Published: 29 October 2021

Publisher's Note: MDPI stays neutral with regard to jurisdictional claims in published maps and institutional affiliations.

Copyright: (c) 2021 by the authors. Licensee MDPI, Basel, Switzerland. This article is an open access article distributed under the terms and conditions of the Creative Commons Attribution (CC BY) license (https:// creativecommons.org/licenses/by/ $4.0 /)$.

\begin{abstract}
Lignin is one of the main components of lignocellulosic biomass and corresponds to the first renewable source of aromatic compounds. It is obtained as a by-product in 100 million tons per year, mainly from the paper industry, from which only $2-3 \%$ is upgraded for chemistry purposes, with the rest being used as an energy source. The richness of the functional groups in lignin makes it an attractive precursor for a wide variety of aromatic compounds. With this aim, we investigated the Pd-catalyzed depolymerization of lignin under mild oxidizing conditions (air, $150{ }^{\circ} \mathrm{C}$, and aqueous $\mathrm{NaOH}$ ) producing oxygenated aromatic compounds, such as vanillin, vanillic acid, and acetovanillone. Palladium catalysts were implemented following different strategies, involving nanoparticles stabilized in water, and nanoparticles were supported on $\mathrm{TiO}_{2}$. Significant conversion of lignin was observed in all cases; however, depending on the catalyst nature and the synthetic methods, differences were observed in terms of selectivity in aromatic monomers, mainly vanillin. All these aspects are discussed in detail in this report, which also provides new insights into the role that Pd-catalysts can play for the lignin depolymerization mechanism.
\end{abstract}

Keywords: lignin; oxidative depolymerization; heterogeneous catalysis; metallic nanoparticles; palladium

\section{Introduction}

Lignin is a biopolymer based on aromatic units that can be obtained in large amounts from lignocellulose following several processes, particularly paper production. Therefore, lignin is a promising source of sustainable aromatic chemicals. However, its transformation into chemicals is still under-developed. This may be due to the large variety of structures existing for lignin. Nevertheless, intensive research is currently being undertaken to find sustainable procedures for viable chemical valorizations, both from lignin and lignin molecular models, in which catalysis plays a significant role [1-8]. Among the routes for lignin upgrading, we are interested in oxidative depolymerization to produce oxygenated aromatic compounds such as aromatic aldehydes, ketones, and carboxylic acids. This transformation is possible in the absence or presence of catalysts, usually under alkaline conditions giving yields in the 1 to $7 \%_{\mathrm{wt}}$ range of vanillin, one of the main products, depending on the lignin botanical origin and extraction process [9-14]. To try to obtain higher yields of oxygenated aromatics from lignin oxidation, a wide variety of catalysts have been 
evaluated as homogeneous (enzymatic, bioinspired, organometallics, and metallic salts) and heterogeneous (supported organometallics, perovskites, metal oxides, and supported metal nanoparticles) and have been described in detail in several reviews to which the reader is invited to refer [1,9-15].

From the literature cited above, it appears that among the catalytic systems, the use of metal nanoparticles in solution seems to have never been reported. One of the advantages can be that such systems involve metallic sites that may have better accessibility to the biopolymer. Our previous work using supported Pt catalysts [16,17], producing limited yields of aromatic compounds, encouraged us to investigate the behavior of homogeneous systems for the oxidative depolymerization of lignin. We selected Pd as metal due to its high oxidative potential as we previously demonstrated on lignin molecular models [18]. Pd-catalysts have been sparsely studied in oxidative depolymerization. For instance, $\mathrm{Pd} / \mathrm{CeO}_{2}$ was assessed in the oxidative depolymerization of an Organosolv lignindelivering vanillin $\left(5 \%{ }_{\mathrm{wt}}\right)$ [19]. Sales and co. have studied Pd-based catalysts extensively for the oxidative depolymerization of lignin. They reported transformation of bagasse lignin in the presence of $\mathrm{Pd} / \gamma-\mathrm{Al}_{2} \mathrm{O}_{3}$, showing clearly that the catalyst increased the yield of vanillin (up to $2.5 \%{ }_{\mathrm{wt}}$ ), syringaldehyde, and $p$-hydroxybenzaldehyde. The kinetic model indicated that the catalyst did not play a role on lignin depolymerization but acted on following transformations [20]. The objective of the present study was to evaluate a range of Pd (0) nanoparticles, in suspension or supported, for lignin oxidative depolymerization in aqueous solvents. Particularly, the effect of nanoparticles in suspension prepared by a straightforward method, or through an innovative flow technique in supercritical conditions, has been assessed for the first time for lignin valorization. The goal was not to present efficient catalytic materials with full characterization through the catalytic cycle but to focus on the role that Pd-species may have on overall reactivity, especially on reactions occurring subsequently after depolymerization. For that, we used spectroscopic techniques with a careful analysis of reaction products to propose different routes forming main aromatic products.

\section{Results and Discussion}

\subsection{Preparation and Characterization of Catalysts}

Various catalysts were implemented in this study. They can be classified into 3 families. Figure 1 illustrates schematically their methods of preparation, which are briefly described below with main characterizations. Additional information can be found in the Materials and Methods section.

Family 1 includes Pd, Au, and PdAu nanoparticles (NPs), stabilized in water by polyvinylpyrrolidone polymer (PVP). These Pd NPs were prepared according to previously reported procedures consisting of reducing $\mathrm{Na}_{2} \mathrm{PdCl}_{4}$ by $\mathrm{NaBH}_{4}$ in the presence of PVP in water [18]. Several Pd to PVP stoichiometries were evaluated from 5 to $25 \mathrm{~mol}_{\text {equiv. }}$ of PVP. Previous results showed that using $10 \mathrm{~mol}_{\text {equiv. }}$ led to the most interesting characteristics in terms of NPs morphology and size, and the absence of aggregation. Here, Pd-PVP system 1a was obtained in a concentration of $3.5 \mathrm{mmol} \mathrm{L}^{-1}$ of Pd. The same procedure was used for preparing $\mathrm{Au}$ and $\mathrm{PdAu} \mathrm{NPs}$ with $\mathrm{HAuCl}_{4}$ and $\mathrm{Na}_{2} \mathrm{PdCl}_{4}$ precursors. In the case of bimetallic NPs, atomic Pd/Au ratios of 3/1 and 1/3 were targeted to exactly adjust the mol $_{\text {equiv. }}$ of precursors. Au-PVP $1 \mathbf{b}$ was obtained in a concentration of $3.5 \mathrm{mmol} \mathrm{L}^{-1}$ of $\mathrm{Au}, \mathrm{Pd}_{3} \mathrm{Au}_{1}$-PVP $1 c_{1}$ was obtained with $2.6 \mathrm{mmol} \mathrm{L}^{-1}$ of $\mathrm{Pd}$ and $0.9 \mathrm{mmol} \mathrm{L}^{-1}$ of $\mathrm{Au}$, and $\mathrm{Pd}_{1} \mathrm{Au}_{3}-\mathrm{PVP} \mathbf{1 c}_{2}$ was obtained with $0.9 \mathrm{mmol} \mathrm{L}^{-1}$ of $\mathrm{Pd}$ and $2.0 \mathrm{mmol} \mathrm{L}^{-1}$ of Au. TEM pictures (Figure 2) present Pd-PVP 1a with a homogeneous dispersion and an average particle size of $3.85 \pm 0.94 \mathrm{~nm}$ (Figure 2a). For Au-PVP 1b, a particle size of $3.71 \pm 1.89 \mathrm{~nm}$ is observed in a very large dispersion ranging from 1 to $11 \mathrm{~nm}$ (Figure $2 \mathrm{~b}$ ). Regarding the bimetallic systems $\mathbf{1 c}_{\mathbf{1 - 2}}$, the average particle size depends on the $\mathrm{Pd} / \mathrm{Au}$ ratio; $2.23 \pm 0.81 \mathrm{~nm}$ is obtained for $\mathrm{Pd}_{3} \mathrm{Au}_{1}-\mathrm{PVP} 1 \mathrm{c}_{1}$ and $6.65 \pm 2.98 \mathrm{~nm}$ for $\mathrm{Pd}_{1} \mathrm{Au}_{3}-\mathrm{PVP}$ $\mathbf{1 c}_{\mathbf{2}}$ (Figure 2c,d). For the latter, brighter dispersion is observed with particle size ranging from 2.5 to $15 \mathrm{~nm}$ vs. 1 to $5 \mathrm{~nm}$ for the former. Very interestingly, indexing some of these 
particles showed that in both cases the atomic $\mathrm{Pd} / \mathrm{Au}$ ratio in the bimetallic particles respects exactly that used for their synthesis. Therefore, no metal segregation occurred during the synthesis.

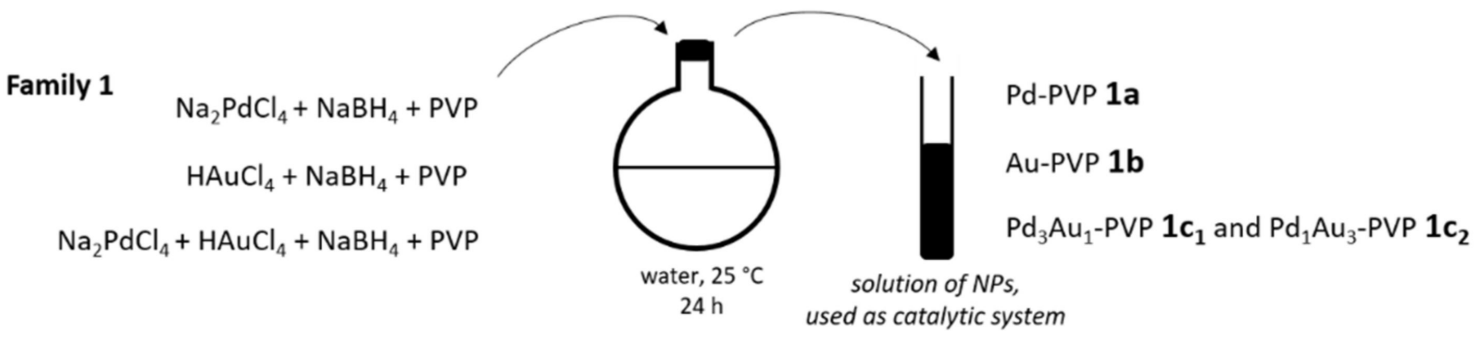

Family 2 acac stands for acetylacetonate hfacac stands for hexafluoroacetyl acetonate

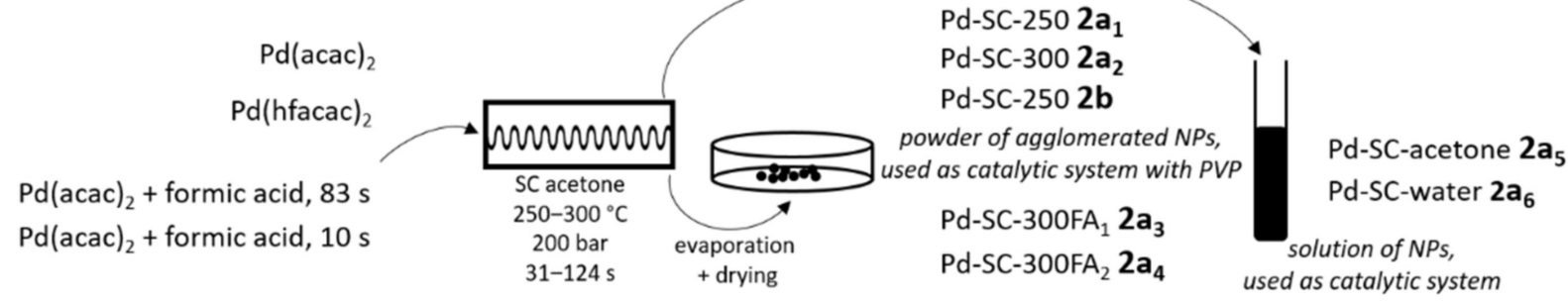

Family 3

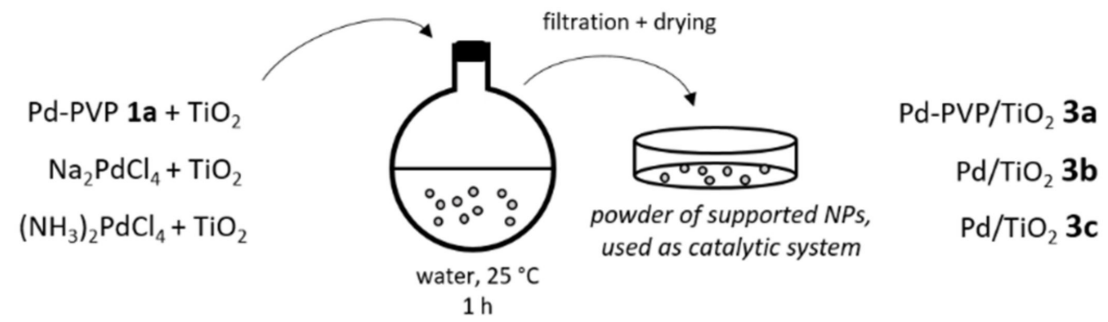

Figure 1. Schematic representation of the preparations of the Pd-containing systems (see Materials and Methods section for details).

Family 2 concerns Pd NPs prepared following an original route investigated in this publication, in the absence of stabilizing agent. Home-established supercritical fluid flow synthesis technique was used for the first time to prepare $\mathrm{Pd}$ nanoparticles in the absence of stabilizing agent, with acetone as reaction medium at 200 bar pressure. About twenty of them were synthesized under fluidic conditions by varying some parameters such as temperature $\left(250\right.$ and $300{ }^{\circ} \mathrm{C}$ ), residence time (31 to $124 \mathrm{~s}$ ), Pd concentration (5 to $10 \mathrm{mmol} \mathrm{L}^{-1}$ ), and the presence of formic acid (as possible additional reducing agent); in a few cases of a surfactant, both may have had an impact on the morphology. The nanoparticles were obtained as powder after acetone evaporation and drying. The most representative samples are presented here after a screening via SEM, XRD, and TEM (see Supplementary Materials for details, Table S1 and Figure S1). For instance, XRD indicates that a temperature of $250{ }^{\circ} \mathrm{C}$ was not sufficient for a complete precursor decomposition whatever the reaction time. Examples of TEM pictures are presented in Figures 3 and 4. The size and the morphology are affected by the reaction conditions. While Pd NPs synthesized in the absence of formic acid present irregular morphology (Figure 3a-c), those prepared in the presence of formic acid display polyhedral morphology (Figure 3d-f). XRD data (Figure S1) deliver lattice constants of $3.991 \AA$ and $3.879 \AA$, respectively. Additionally, those prepared in the presence of formic acid showed high stability both in acetone and water solution. Further investigations of the synthesis of Pd NPs in the presence of formic acid showed that the morphology depends on the ratio formic acid/Pd used during the 
synthesis, surfactant, and residence time. Examples are given in Figure 4. While working with a ratio $10 / 1$, icosahedron and triangular bipyramid (or triangular plate) morphologies are observed (Figure 4a), and octahedron appeared when working with a ratio 20/1 (in the presence of oleylamine) (Figure $4 \mathrm{~b}$ ). Rods or bars were observed when excluding oleylamine but increasing the residence time to $83 \mathrm{~s}$ (versus $30 \mathrm{~s}$ ) (Figure 4c).
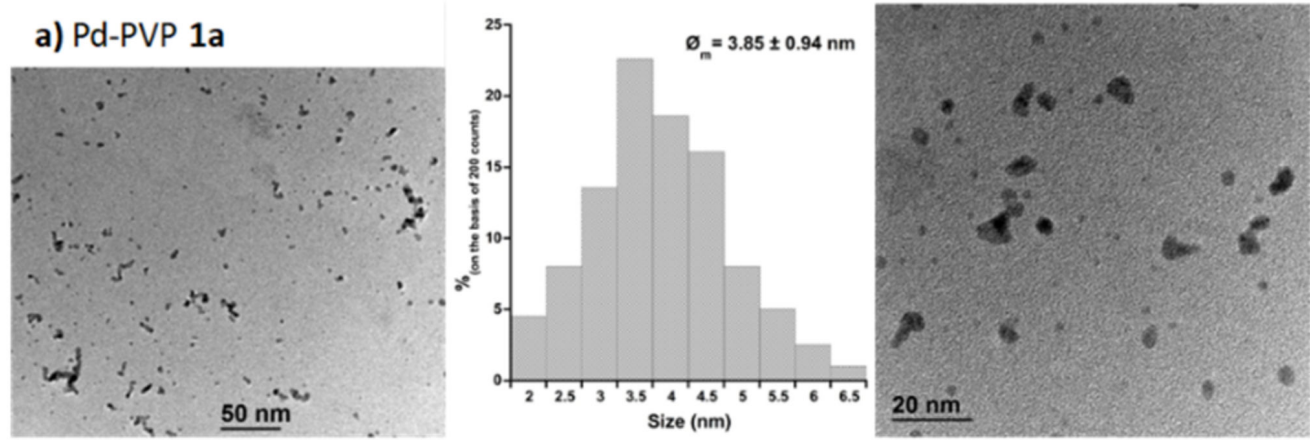

\section{b) Au-PVP 1b}
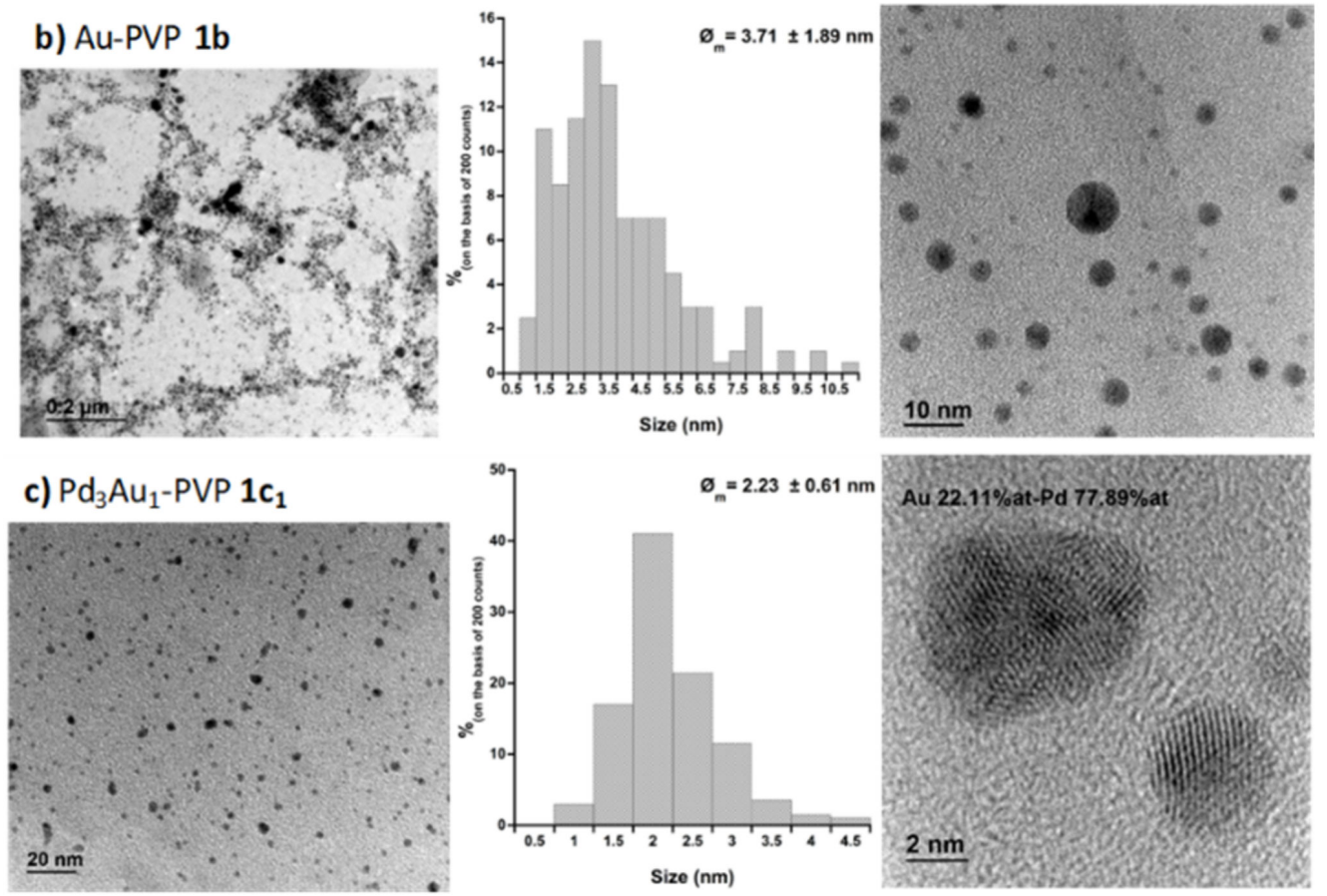

\section{d) $\mathrm{Pd}_{1} \mathrm{Au}_{3}-\mathrm{PVP} 1 \mathrm{c}_{2}$}
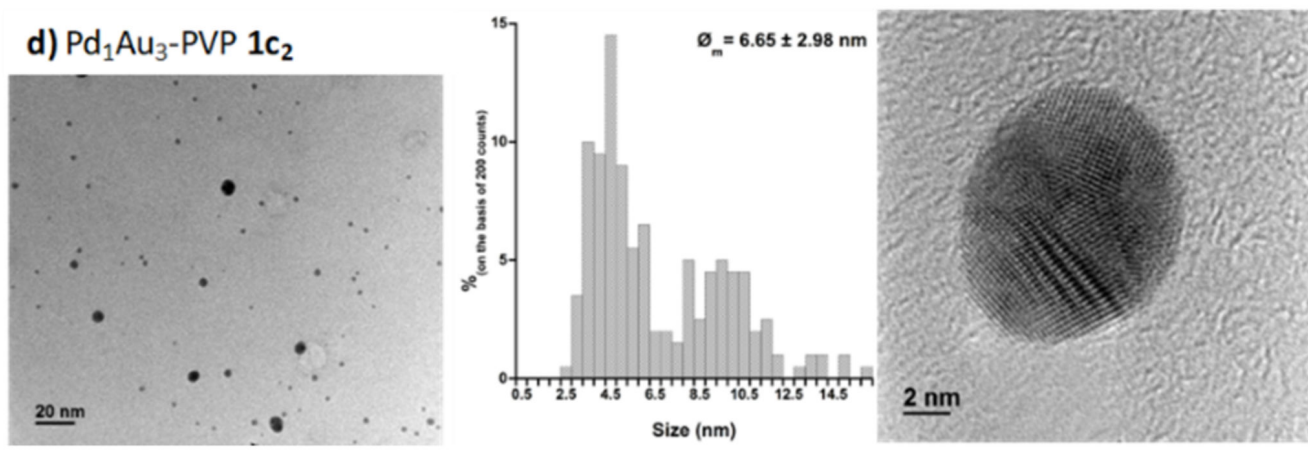

Figure 2. TEM pictures and size distribution of the different nanoparticle systems of Family 1. (a) Obtained from $\mathrm{Na}_{2} \mathrm{PdCl}_{4}$. (b) Obtained from $\mathrm{HAuCl}_{4}$. (c,d) Obtained from $\mathrm{Na}_{2} \mathrm{PdCl}_{4}$ and $\mathrm{HAuCl}_{4}$. 

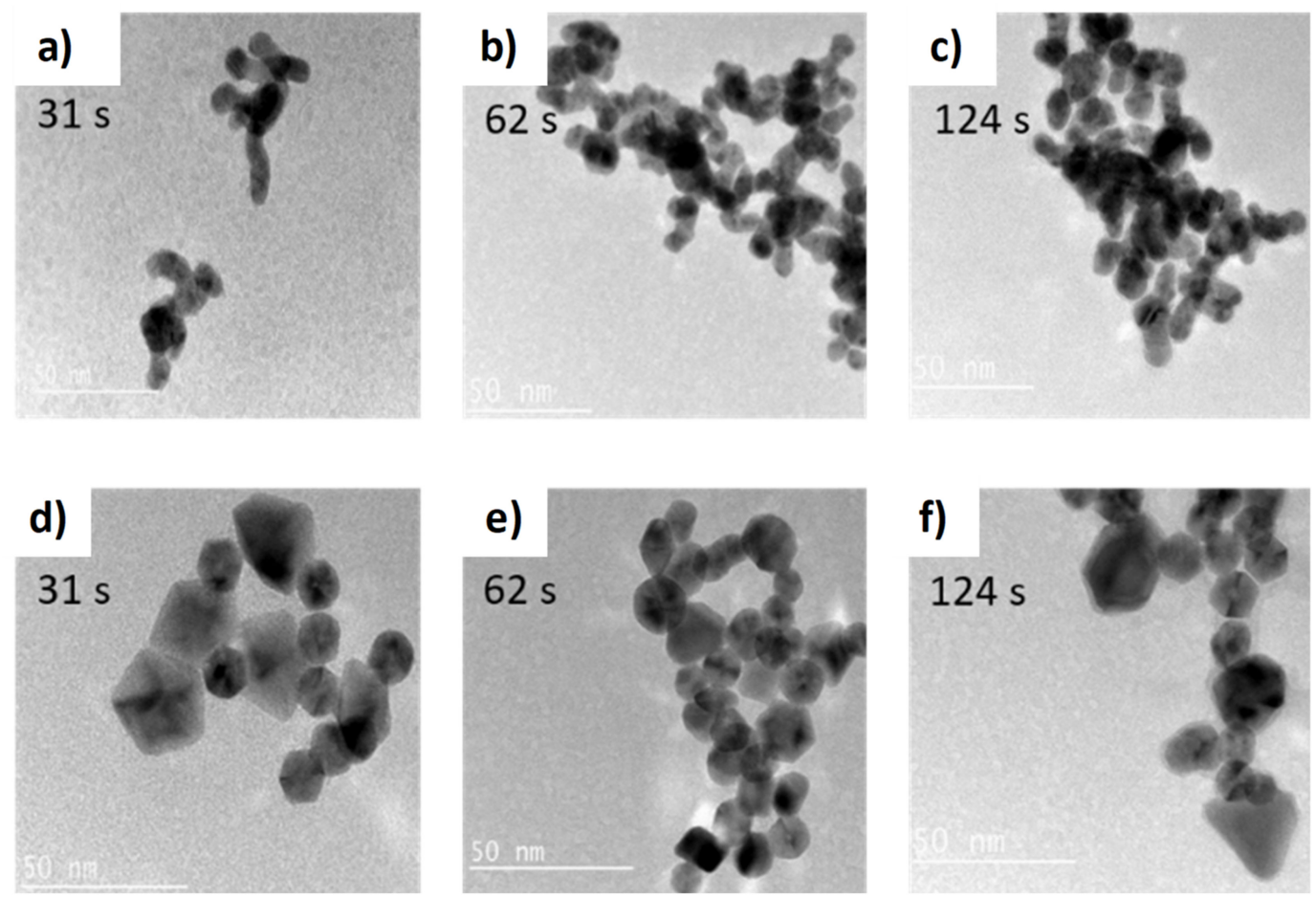

Figure 3. TEM pictures of Pd NPs prepared by the supercritical fluidic approach from $\mathrm{Pd}(\mathrm{acac})_{2}$. Influence of reaction time. $(\mathbf{a}-\mathbf{c})$ in the absence of formic acid, $(\mathbf{d}-\mathbf{f})$ in the presence of formic acid.
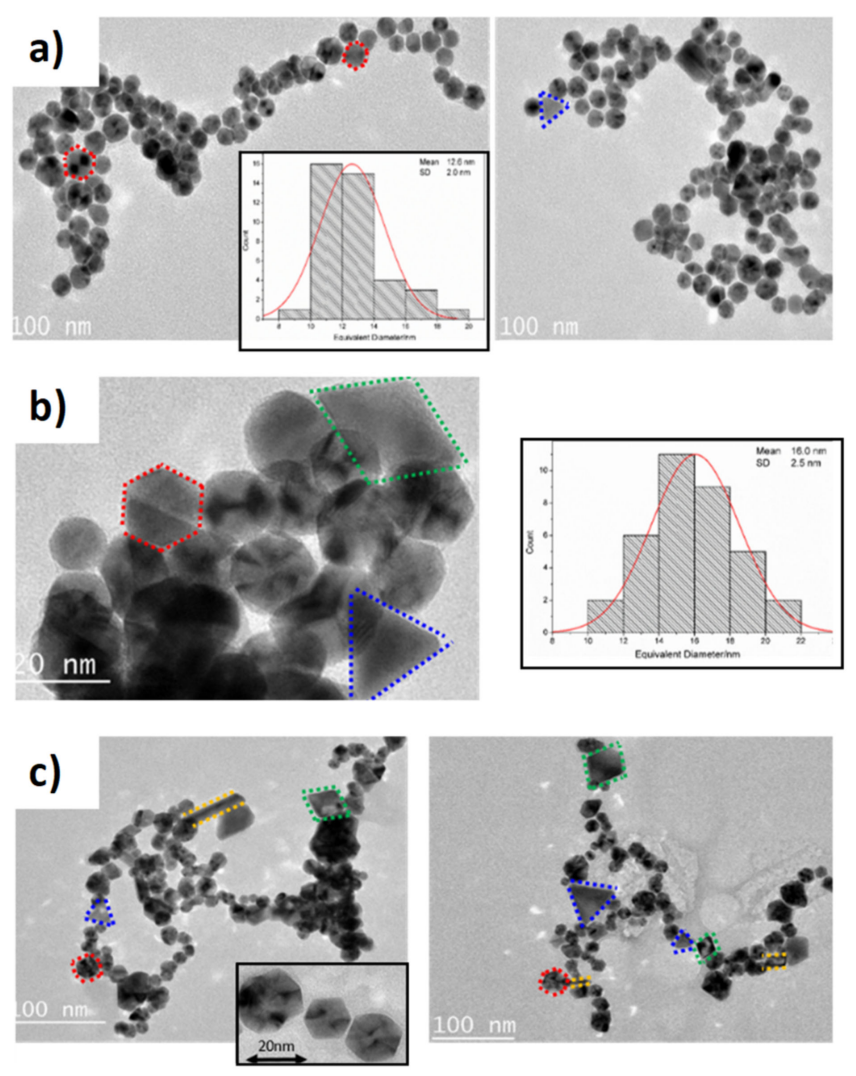

Figure 4. TEM pictures and size distribution of Pd NPs prepared by the supercritical fluidic approach from $\mathrm{Pd}(\mathrm{acac})_{2}$. Influence of some synthesis parameters. (a) $0.005 \mathrm{~mol} \mathrm{~L}^{-1}$ of $\mathrm{Pd}, 0.05 \mathrm{~mol} \mathrm{~L}^{-1}$ of formic acid (10/1), and $30 \mathrm{~s}$. (b) $0.005 \mathrm{~mol} \mathrm{~L}^{-1}$ of Pd, $0.10 \mathrm{~mol} \mathrm{~L}-1$ of formic acid (20/1), $0.02 \mathrm{~mol} \mathrm{~L}^{-1}$ of oleylamine (4/1), and $30 \mathrm{~s}$. (c) $0.01 \mathrm{~mol} \mathrm{~L}^{-1}$ of Pd, $0.20 \mathrm{~mol} \mathrm{~L}^{-1}$ of formic acid (20/1), and $83 \mathrm{~s}$. 
On the basis of these first data, materials $\mathbf{2} \mathbf{a}_{1-4}$ obtained from $\mathrm{Pd}(\mathrm{acac})_{2}$ and $\mathbf{2} \mathbf{b}$ obtained from $\mathrm{Pd}(\mathrm{hfacac})_{2}$, as powders after acetone evaporation and drying (see Figure 1 and Table S1 for synthesis conditions), were deeper characterized by TEM (Figure 5). Examples of pictures for Pd-SC $\mathbf{2} \mathbf{a}_{2}$ and Pd-SC $\mathbf{2} \mathbf{b}$ show small Pd particles with an average size of ca. 8-12 nm, indicating particle aggregation upon drying, which was not the case in synthesis acetone. Plane indexing confirms the presence of Pd (0) (Figure S2). Additionally, for Pd-SC 2b prepared from Pd(hfacac) 2 , EDX indicates the presence of inorganic impurities for any possible reason. To prevent aggregation of Pd NPs, for catalytic applications the synthesis acetone was displaced by fresh acetone or water, producing materials $\mathbf{2} \mathbf{a}_{5}$ and $2 \mathbf{a}_{6}$, respectively.
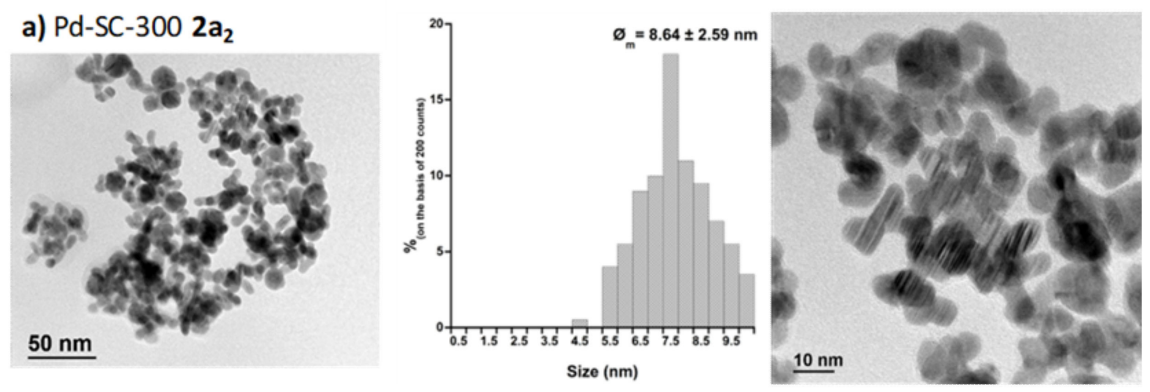

b) Pd-SC-300 2b
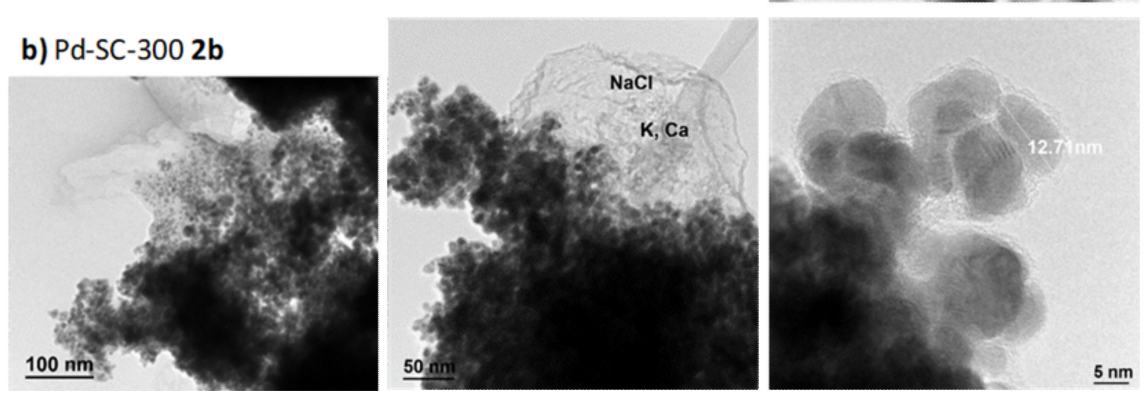

Figure 5. TEM pictures of the different nanoparticle systems of Family 2 prepared by the supercritical fluidic approach in acetone. (a) Obtained from $\mathrm{Pd}(\mathrm{acac})_{2}$ at $300{ }^{\circ} \mathrm{C}$. (b) Obtained from $\mathrm{Pd}(\mathrm{hfacac})_{2}$ at $300{ }^{\circ} \mathrm{C}$.

To summarize, the study on the synthesis under supercritical fluidic conditions of Family $\mathbf{2}$ materials indicates that stabilized Pd NPs of relatively small size and controlled morphology can be obtained even in the absence of stabilizer during their synthesis. The very short reaction time necessary for their formation is one of the parameters preventing coalescence despite aggregation.

Family 3 concerns Pd nanoparticles immobilized on a support (see Figure 1). Three different materials were prepared following common procedures. The first one was obtained by the deposition of preformed Pd NPs Pd-PVP 1a on $\mathrm{TiO}_{2}$ P25 [18]. Among other possible supports such as $\mathrm{ZrO}_{2}$ or carbons, $\mathrm{TiO}_{2}$ has been chosen due to its relatively good hydrothermal stability and ability to stabilize Pd nanoparticles with a narrow size distribution [16]. To afford best conditions for depositing the Pd NPs onto the support, the $\mathrm{pH}$ of the aqueous solution was adjusted to 2 . After stirring for $1 \mathrm{~h}$, the solid material was filtered, dried, calcined, and reduced, affording Pd-PVP/ $\mathrm{TiO}_{2} 3$ a with $2.20 \%$ wt of $\mathrm{Pd}$. Next, $\mathrm{Pd} / \mathrm{TiO}_{2} 3 \mathrm{~b}$ and $3 \mathbf{c}$ materials were prepared by usual incipient wetness impregnation of $\mathrm{TiO}_{2} \mathrm{P} 25$ by aqueous solution of $\mathrm{Na}_{2} \mathrm{PdCl}_{4}$ and $\left(\mathrm{NH}_{3}\right)_{4} \mathrm{PdCl}_{2}$, respectively. Following impregnation, the materials were calcined and reduced, producing solids with $2.75 \%{ }_{\mathrm{wt}}$ and $2.45 \%$ wt of Pd, respectively (see Table 1 ). Figure 6 presents TEM pictures. As we previously reported, the average particles of $\mathbf{3 a}$ were slightly smaller than 1a, with a narrow average size of $1.55 \pm 0.39 \mathrm{~nm}$ (due to partial dissolution with acidic $\mathrm{pH}$ ) [18], and with a homogeneous dispersion on the support (Figure 6a). $\mathrm{Pd} / \mathrm{TiO}_{2} 3 \mathbf{b}-\mathrm{c}$ prepared showed larger dispersion of particle size, with an average of $2.04 \pm 0.97 \mathrm{~nm}$ and $2.42 \pm 0.57 \mathrm{~nm}$, respectively, as expected for this preparation method (Figure 6b,c). Note that BET analyses 
showed surface area in the range of $54-58 \mathrm{~m}^{2} \mathrm{~g}^{-1}$, very close to that of the parent $\mathrm{TiO}_{2}$ support $\left(57 \mathrm{~m}^{2} \mathrm{~g}^{-1}\right)$ (see Table 1$)$.

Table 1. Characteristics of materials of Family 3.

\begin{tabular}{ccc}
\hline Catalyst & $\begin{array}{c}\text { Pd Content } \pm \mathbf{0 . 0 5} \\
\left(\mathbf{\%}_{\mathbf{w t}}\right)\end{array}$ & $\begin{array}{c}\mathbf{S}(\mathbf{B E T}) \pm \mathbf{0 . 5} \\
\left(\mathbf{m}^{\mathbf{2}} \mathbf{g}^{-\mathbf{1}}\right)\end{array}$ \\
\hline $\mathrm{TiO}_{2}$ & - & 57 \\
$\mathrm{Pd}-\mathrm{PVP}_{2} \mathrm{TiO}_{2} \mathbf{3 a}$ & 2.20 & 57 \\
$\mathrm{Pd} / \mathrm{TiO}_{2}$ from $\mathrm{Na}_{2} \mathrm{PdCl}_{4} \mathbf{3 b}$ & 2.75 & 54 \\
$\mathrm{Pd} / \mathrm{TiO}_{2}$ from $\left(\mathrm{NH}_{3}\right)_{4} \mathrm{PdCl}_{2} 3 \mathbf{c}$ & 2.45 & 58 \\
\hline
\end{tabular}

a) $\mathrm{Pd}-\mathrm{PVP} / \mathrm{TiO}_{2} 3 \mathrm{a}$

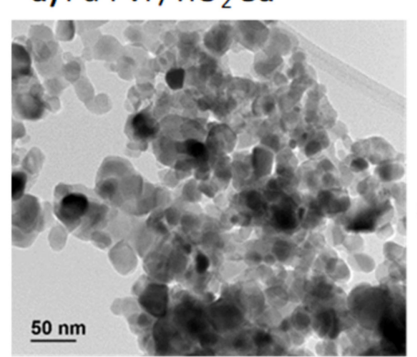

b) $\mathrm{Pd} / \mathrm{TiO}_{2} 3 \mathbf{b}$

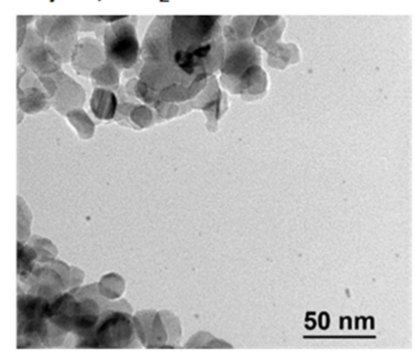

c) $\mathrm{Pd} / \mathrm{TiO}_{2} 3 \mathrm{c}$

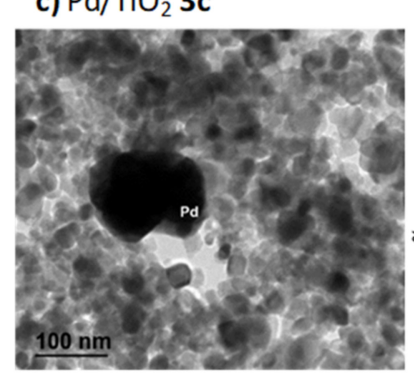

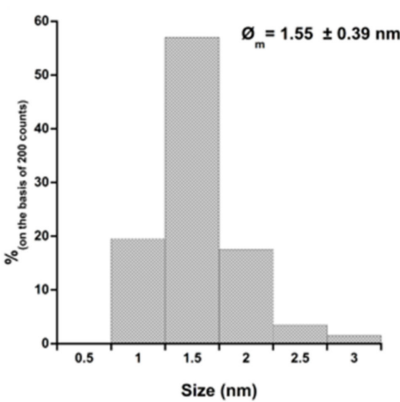
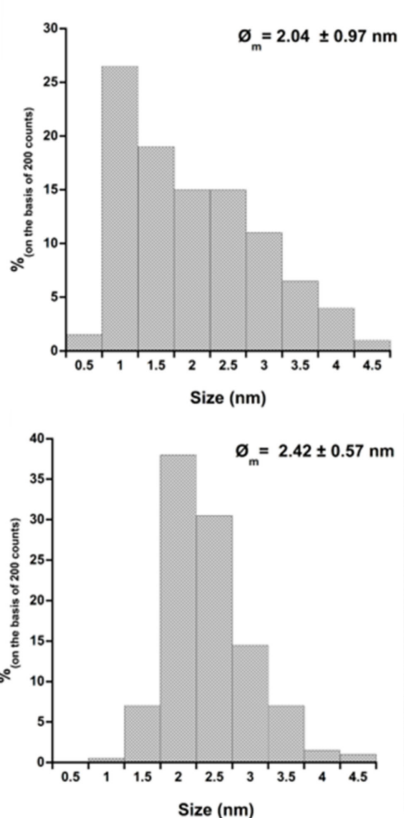
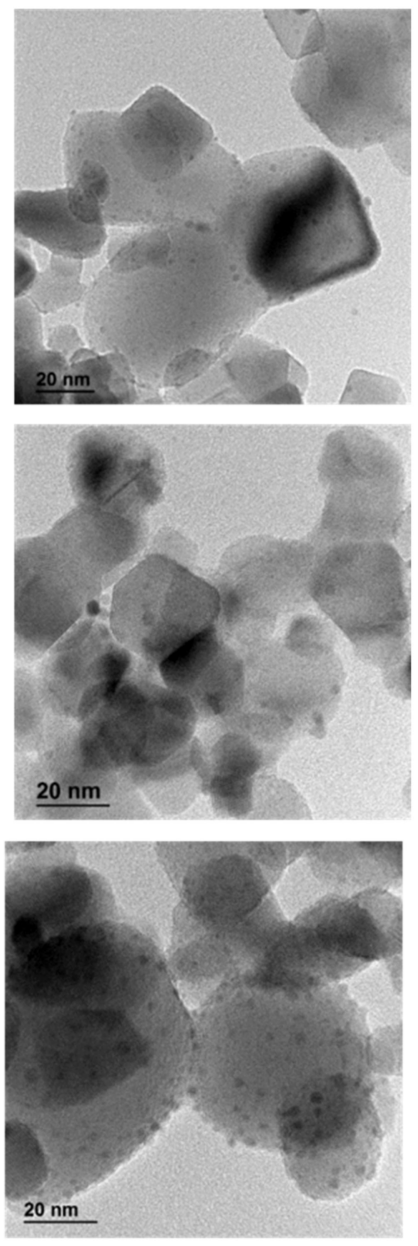

Figure 6. TEM pictures and particle size distribution of the different solids of Family 3. (a) Obtained by impregnation of Pd-PVP 1 a on $\mathrm{TiO}_{2}$. (b) Obtained by impregnation of $\mathrm{Na}_{2} \mathrm{PdCl}_{4}$ on $\mathrm{TiO}_{2}$. (c) Obtained by impregnation of $\left(\mathrm{NH}_{3}\right)_{2} \mathrm{PdCl}_{4}$ on $\mathrm{TiO}_{2}$.

\subsection{Lignin Reactant}

Kraft lignin used in this study was provided by FCBA. It was isolated from a Pinus pinaster black liquor from paper industry following a reported procedure [9,21]. In short, $\mathrm{CO}_{2}$ bubbling in the black liquor precipitated lignin by lowering $\mathrm{pH}$ from 10 to 8 . Lignin was recovered by centrifugation and washed with a $2 \%{ }_{\mathrm{wt}} \mathrm{H}_{2} \mathrm{SO}_{4}$ aqueous solution. Purity was estimated at $90-96 \%$, due to the presence of ca. $1.5 \%_{\mathrm{wt}}$ of ashes and $2 \%_{\mathrm{wt}}$ of sulfur.

As previously reported [9,16], this Kraft lignin was characterized using complementary techniques. In addition to elemental analysis (see Table S2), spectroscopic methods allowed one to improve one's knowledge of the structure. FTIR-ATR (Figure 7) confirms the softwood origin of this lignin, particularly through the bands at 1270,1125, 855, and 
$810 \mathrm{~cm}^{-1}$, corresponding to guaiacyl (G) units, which is coherent with the absence of bands expected at 1326 and $1115 \mathrm{~cm}^{-1}$ for syringyl (S) units. Next, FTIR displays bands at 1600, 1515 , and $1425 \mathrm{~cm}^{-1}$ attributed to aromatic rings, at 2960,1850 and $1460 \mathrm{~cm}^{-1}$ to alkyl moieties, and at 1715 and $1705 \mathrm{~cm}^{-1}$ to unconjugated carbonyls. Noticeably, FTIR spectrum presents clearly a band at $1365 \mathrm{~cm}^{-1}$ corresponding to free phenolic hydroxyls.

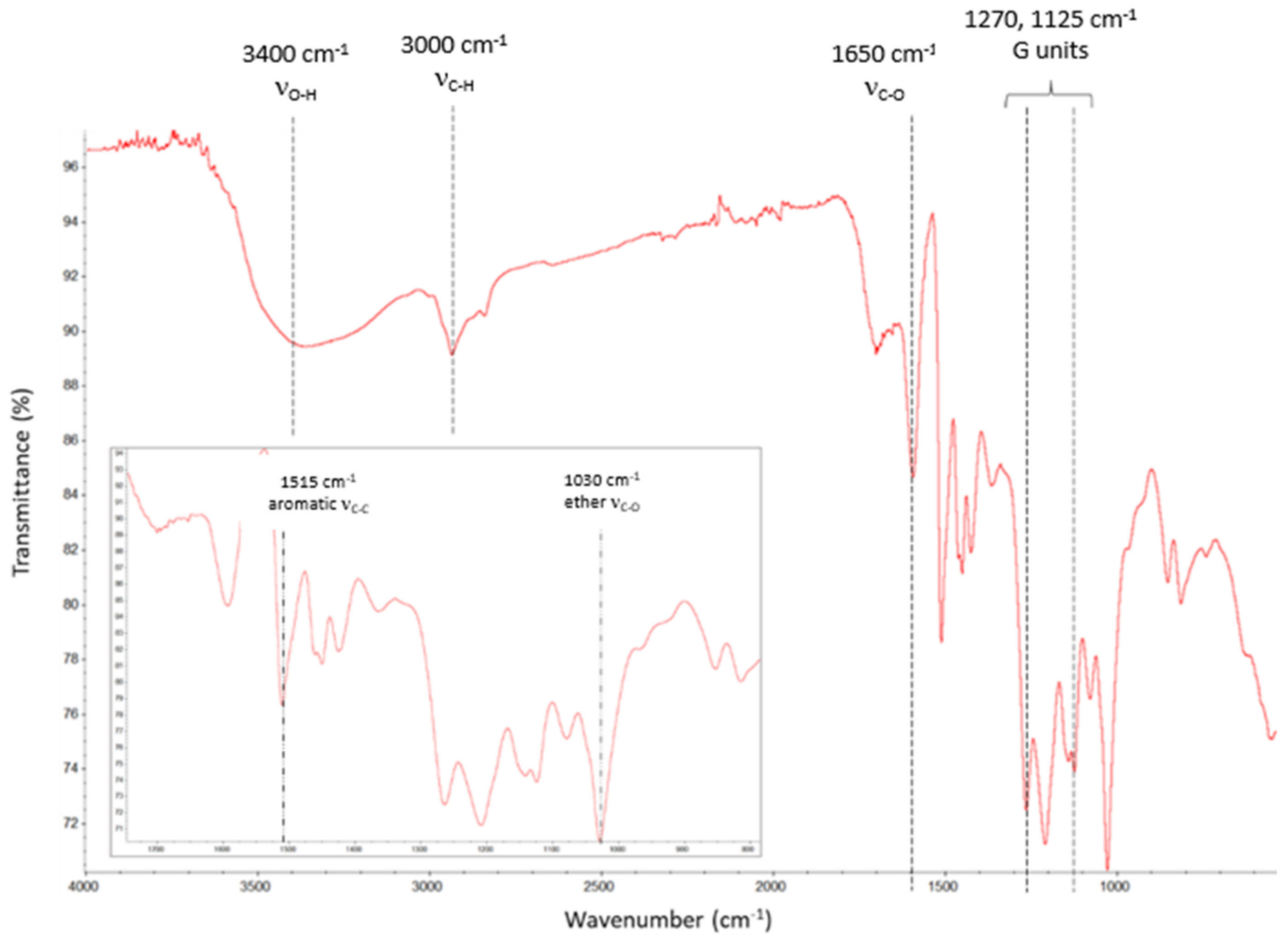

Figure 7. FTIR-ATR spectrum of Kraft lignin reactant.

Structural analysis with NMR, already reported elsewhere [9], was not very informative for the purpose of this study (Figure S3 and Table S2). However, Kraft lignin was further characterized through advanced NMR techniques. First, ${ }^{31} \mathrm{P}$ NMR was very useful to quantify the $\mathrm{OH}$ groups present within the material as well as their nature after derivatization with 2-chloro-4,4,5,5-tetramethyl-1,3,2-dioxaphospholane (TMDP) (see Table 2 and Figure S4). As expected from lignin structure, when comparing data from ${ }^{31} \mathrm{P} N \mathrm{NMR}$ and elemental analyses, all the $\mathrm{O}$ atoms composing lignin are not found as $\mathrm{OH}$ groups, whatever the nature, but are mostly engaged in ether bonds (ca. 70\%).

Table 2. Quantitative data concerning OH groups in the initial lignin, obtained by derivatization with TMDP and classified by nature (see Figure S3). Comparison with elemental analysis data.

\begin{tabular}{|c|c|}
\hline $\begin{array}{c}\text { OH Group } \\
\left({ }^{31} \text { P NMR Chemical Shift }\right)\end{array}$ & $\begin{array}{c}\text { OH Content } \pm 0.05 \\
\left(\text { mmol }_{\text {lignin }}{ }^{-1}\right)\end{array}$ \\
\hline aliphatic (149-145 ppm) & 1.75 \\
\hline syringyl and condensed units (144-140 ppm) & 1.35 \\
\hline guaiacyl (140-138 ppm) & 1.70 \\
\hline p-hydroxyphenyl (138-133 ppm) & 0.15 \\
\hline carboxylic acids (135-133 ppm) & 0.30 \\
\hline Total & 5.25 \\
\hline Analytical Method & $\begin{array}{l}\text { O Content } \\
\left(\%_{w t}\right)\end{array}$ \\
\hline${ }^{31} \mathrm{P} N M R$ & $8.40 \pm 0.05$ \\
\hline elemental analysis & $29 \pm 0.5$ \\
\hline ratio of $\mathrm{O}$ analyzed by ${ }^{31} \mathrm{P} \mathrm{NMR}$ & $29 \%$ \\
\hline
\end{tabular}


Then, HSQC analysis delivered information on the inter-unit linkages that could be counted via a semi-quantitative approach (Figure 8) [22]. Oxygenated aliphatic region (Figure $8 \mathrm{a} ; \delta_{\mathrm{H}} 2.6-6 \mathrm{ppm} ; \delta_{\mathrm{C}} 50-105 \mathrm{ppm}$ ) corresponding to aliphatic $\mathrm{C}-\mathrm{H}$ next to an oxygen shows correlations attributed to the interunit bonds as $\beta-\mathrm{O}-4(\mathrm{~A}), \beta-\beta(\mathrm{B})\left(\mathrm{B}_{\gamma}-\delta_{\mathrm{H}} / \delta_{\mathrm{C}}\right.$ $4.7 / 72 \mathrm{ppm})$, and $\beta-5$ (C) $\left(\mathrm{C}_{\alpha}-\delta_{\mathrm{H}} / \delta_{\mathrm{C}} 5.5 / 87 \mathrm{ppm} ; \mathrm{C}_{\beta}-\delta_{\mathrm{H}} / \delta_{\mathrm{C}} 3.55 / 54 \mathrm{ppm}\right)$. The main interunit bonds $\beta-\mathrm{O}-4$ gave three well characteristic correlations $\left(\mathrm{A} / \mathrm{A}^{\prime} / \mathrm{A}^{\prime \prime}\right)$ as $\mathrm{A}_{\alpha}\left(\delta_{\mathrm{H}} / \delta_{\mathrm{C}}\right.$ $4.85 / 73 \mathrm{ppm}), \mathrm{A}_{\beta}(\mathrm{G} / \mathrm{H})\left(\delta_{\mathrm{H}} / \delta_{\mathrm{C}} 4.35 / 83 \mathrm{ppm}\right)$, and $\mathrm{A}_{\gamma}\left(\delta_{\mathrm{H}} / \delta_{\mathrm{C}} 3.75 / 61 \mathrm{ppm} ; \mathrm{A}^{\prime} \gamma^{-} \delta_{\mathrm{H}} / \delta_{\mathrm{C}}\right.$ $\left.4.2 / 72 \mathrm{ppm} ; \mathrm{A}^{\prime \prime}{ }^{-} \delta_{\mathrm{H}} / \delta_{\mathrm{C}} 3.85 / 64 \mathrm{ppm}\right)$. Residual carbohydrates were also observed $\left(\delta_{\mathrm{H}} / \delta_{\mathrm{C}}\right.$ $3.2 / 63 \mathrm{ppm}$ ). The aromatic region (Figure $8 \mathrm{~b} ; \delta_{\mathrm{H}} 4.9-8 \mathrm{ppm} ; \delta_{\mathrm{C}} 90-160 \mathrm{ppm}$ ) shows correlations corresponding mainly to the guaiacyl $(\mathrm{G})$ units $\left(\mathrm{G}_{2}-\delta_{\mathrm{H}} / \delta_{\mathrm{C}} 7.15 / 110 \mathrm{ppm} ; \mathrm{G}_{5}-\delta_{\mathrm{H}} / \delta_{\mathrm{C}}\right.$ $\left.7.05 / 118 \mathrm{ppm} ; \mathrm{G}_{6}-\delta_{\mathrm{H}} / \delta_{\mathrm{C}} 7.02 / 120 \mathrm{ppm}\right)$ and $p$-hydroxyphenyl units $(\mathrm{H})\left(\mathrm{H}_{2,6}-\delta_{\mathrm{H}} / \delta_{\mathrm{C}}\right.$ $6.20 / 126 \mathrm{ppm}$ ). Noticeably, there is no correlation characteristic from syringyl (S) units, as expected from a Kraft lignin issued form pine wood. Correlation attributed to ferulic moieties (FA) $\left(\mathrm{FA}_{2}-\delta_{\mathrm{H}} / \delta_{\mathrm{C}} 7.45 / 117 \mathrm{ppm} ; \mathrm{FA}_{6}-\delta_{\mathrm{H}} / \delta_{\mathrm{C}} 7.25 / 122 \mathrm{ppm}\right)$ was also observed. Semi-quantitative analysis delivered the proportion of interunit bonds expressed per 100 aromatic $\mathrm{CH}$ units as $6.5 \beta-\mathrm{O}-4,3.0 \beta-\beta$ and $2.0 \beta-5$, applying the reported method [22] with a $\mathrm{G} / \mathrm{S} / \mathrm{H}$ composition of $88 / 0 / 12$ via the volume integration. All these data agree with those generally reported in the literature for similar lignins.
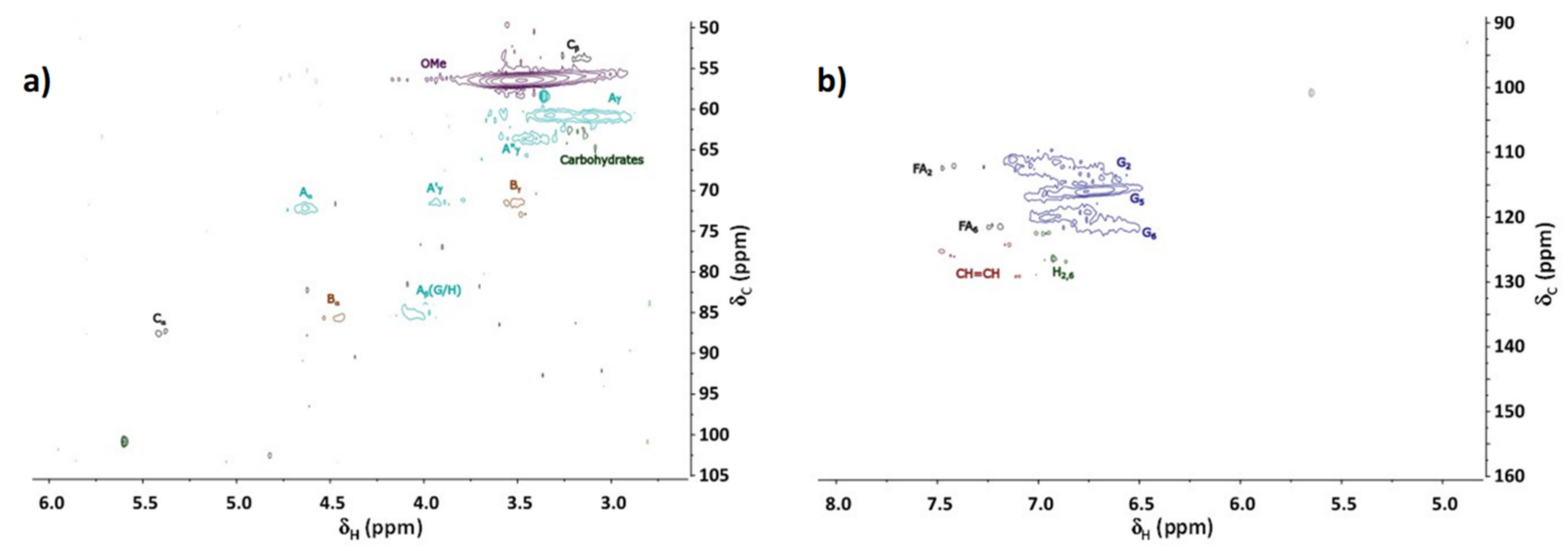

Figure 8. HSQC spectrum (48 scans) of initial Kraft lignin. (a) Oxygenated region; (b) aromatic region.

\subsection{Lignin Depolymerization Studies}

Lignin oxidation was carried out under basic conditions at $150{ }^{\circ} \mathrm{C}$ in a batch reactor equipped with an air ballast to maintain a constant pressure. The reaction starting time was defined once the reactor reached the desired temperature under inert atmosphere, before being pressurized under air (20 bars). After removing the solid catalyst (if any) by filtration, the reaction mixture was acidified to $\mathrm{pH} 1$ by dropwise addition of a $10 \% \mathrm{HCl}$ solution. The precipitate was recovered from the aqueous solution by centrifugation leading to the so-called"acid-insoluble phase", which corresponds mainly to the residual (insoluble) part of lignin. Extraction from the aqueous solution with $\mathrm{CH}_{2} \mathrm{Cl}_{2}$ led, after $\mathrm{CH}_{2} \mathrm{Cl}_{2}$ evaporation and drying, to the "organic phase", corresponding to the mixture of organic products such as aromatics. Then, the aqueous solution was evaporated and the residue was dissolved with THF to remove inorganic salts. After filtration, THF evaporation, and drying, this produced the "aqueous phase", corresponding to the mixture of water-soluble organic products such as aliphatic carboxylic acids (See Material and Methods for details). Figure 9 presents the conversion of lignin in terms of fractions described above, and Figure 10 presents the yields of the aromatic compounds analyzed in the organic fraction. Reaction conditions are described in Figures 9 and 10. 


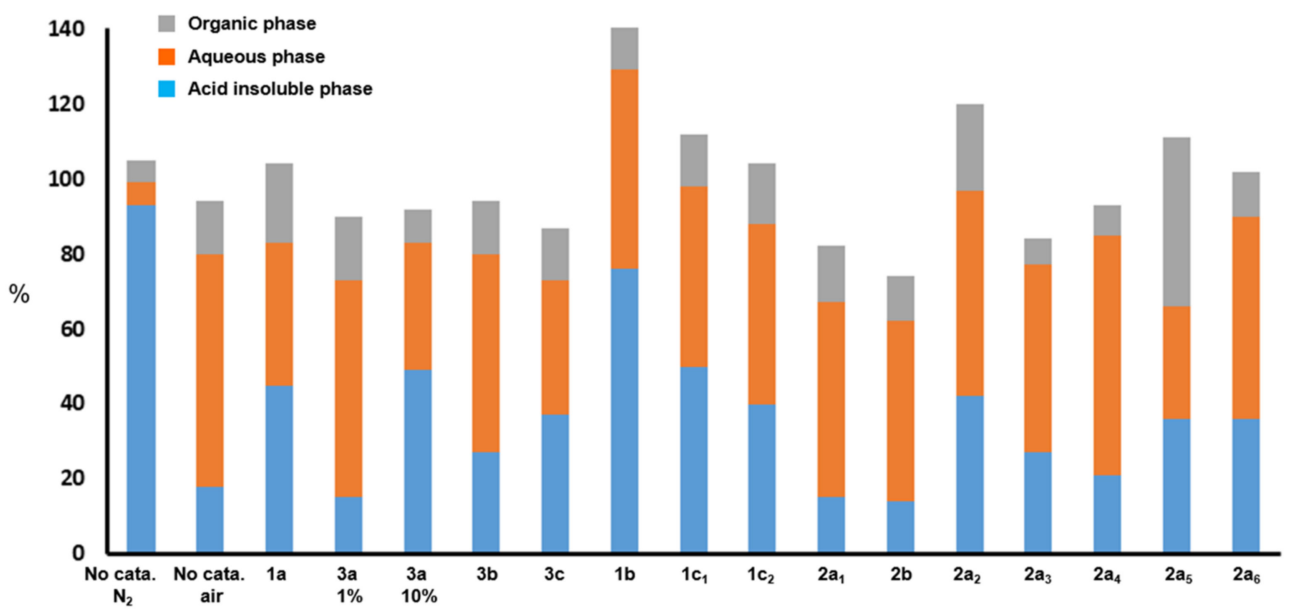

Figure 9. Influence of the catalysts on the fractionation of the reaction mixture after lignin depolymerization $\left(150^{\circ} \mathrm{C}\right.$, pair 20 bar, $1 \mathrm{~h}, \mathrm{C}_{\text {lignin }} 5 \mathrm{~g} \mathrm{~L}^{-1}, \mathrm{C}_{\mathrm{NaOH}} 10 \mathrm{~g} \mathrm{~L}^{-1}$, and $\mathrm{C}_{\mathrm{M}} 0.05-0.5 \mathrm{~g} \mathrm{~L}^{-1}[\mathrm{M}=\mathrm{Pd}$ or $\mathrm{Au}]$ ); $1 \%$ refers to a mass of $\mathrm{Pd}$ corresponding to $1 \%{ }_{\mathrm{wt}}$ of the lignin giving a Pd loading of $0.05 \mathrm{~g} \mathrm{~L}^{-1}$, and $10 \%$ refers to a mass of Pd corresponding to $10 \%{ }_{\mathrm{wt}}$ of the lignin giving a Pd loading of $0.5 \mathrm{~g} \mathrm{~L}^{-1}$.

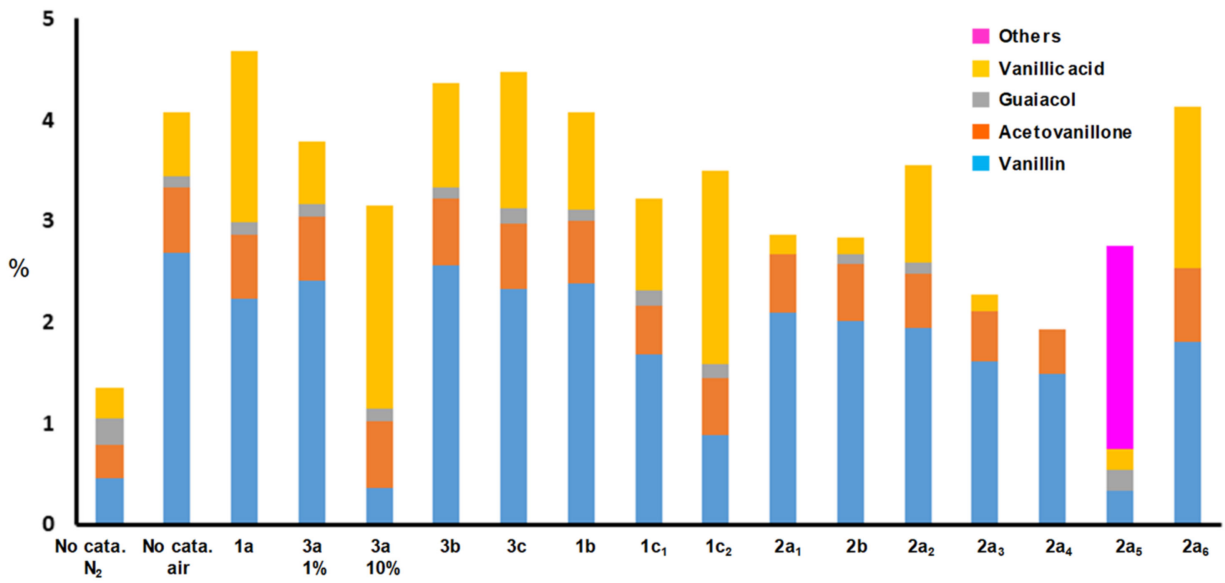

Figure 10. Influence of the catalysts on the yields of aromatic contained in the organic phase after lignin depolymerization $\left(150{ }^{\circ} \mathrm{C}, \mathrm{P}_{\text {air }} 20 \mathrm{bar}, 1 \mathrm{~h}, \mathrm{C}_{\text {lignin }} 5 \mathrm{~g} \mathrm{~L}^{-1}, \mathrm{C}_{\mathrm{NaOH}} 10 \mathrm{~g} \mathrm{~L}^{-1}, \mathrm{C}_{\mathrm{M}} 0.05-0.5 \mathrm{~g} \mathrm{~L}^{-1}\right.$ $[\mathrm{M}=\mathrm{Pd}$ or $\mathrm{Au}]) ; 1 \%$ refers to a mass of Pd corresponding to $1 \%{ }_{\mathrm{wt}}$ of the lignin giving a Pd loading of $0.05 \mathrm{~g} \mathrm{~L}^{-1}$, and $10 \%$ refers to a mass of Pd corresponding to $10 \%_{\mathrm{wt}}$ of the lignin giving a Pd loading of $0.5 \mathrm{~g} \mathrm{~L}^{-1}$.

\subsubsection{Depolymerization in the Absence of Catalyst}

In initial experiments, lignin was treated in the absence of catalyst under inert atmosphere $\left(\mathrm{N}_{2}\right)$. The first experiment was stopped once the desired temperature was attained $\left(150{ }^{\circ} \mathrm{C}\right)$, and a second experiment was conducted over $1 \mathrm{~h}$ at $150{ }^{\circ} \mathrm{C}$. Both reactions gave the same results in terms of fractionation: $93-100 \%$ of acid-insoluble phase, $6-8 \%$ of aqueous phase, and $6 \%$ of organic phase (Figure 9 ). Deep analysis of the organic phases revealed that both contain ca. $0.5 \%$ of vanillin, $0.2-0.3 \%$ of acetovanillone, $0.2 \%$ of guaiacol, and a few vanillic acid (Figure 10). Therefore, heating the reaction mixture under inert atmosphere did not lead to lignin depolymerization, validating the notion that an oxidant has to be present for deep reactivity.

As a consequence, treating lignin with air under same conditions gave very different results depending on the presence or not of a catalyst. In the absence of catalyst, the acidinsoluble phase proportion dropped from 93 to $18 \%$, confirming the reactive role of the air (or $\mathrm{O}_{2}$ ) atmosphere in lignin depolymerization. At the same time, the proportion of the organic phase (aromatic products) increased from 6 to $14 \%$ and that of aqueous phase from 
6 to $62 \%$. Thus, the main part of the light product issued from lignin depolymerization was present within the aqueous phase due to favorable formation of water-soluble compounds. Analysis of the organic phase revealed that ca. $2.5 \%$ yield of vanillin was obtained, besides other aromatic compounds in a range of $0.5 \%$ yield.

\subsubsection{Depolymerization in the Presence of Catalyst Families $\mathbf{1}$ and $\mathbf{2}$}

The addition of a catalyst modified the proportions of the different fractions. When using Pd NPs-PVP 1a (at loading of $0.05 \mathrm{~g} \mathrm{~L}^{-1}$ of Pd), the proportion of the acid-insoluble phase increased from 18 to $45 \%$ and while that of the aqueous phase dropped from 60 to $40 \%$, while that of the organic phase increased slightly from 15 to $20 \%$. The distribution of organic aromatics present in the latter remained almost identical. Attempts to improve the catalyst activity and selectivity by changing $\mathrm{Pd}$ to Au and developing bimetallic systems of PdAu did not deliver the expected results. Au-PVP $\mathbf{1 b}$ appeared to be less active than Pd-PVP 1a, and lignin conversion stayed limited to $25 \%$ without strongly affecting the yields of identified aromatic compounds. This partly contrasts with the results observed in previous study using $\mathrm{Au} / \mathrm{TiO}_{2}$ where very high lignin reactivity (conversion over 90\%) was obtained despite very low yield of aromatic compounds [16]. When using bimetallic PdAu systems 1c, despite good reactivity with 50-60\% of lignin conversion, yield of vanillin dropped below $2 \%$ (ca. 1.7\% and 1.0\% with $\mathrm{Pd}_{3} \mathrm{Au}_{1} \mathbf{1} \mathbf{c}_{1}$ and $\mathrm{Pd}_{1} \mathrm{Au}_{3} \mathbf{1} \mathbf{c}_{2}$, respectively) and total yields of identified aromatic products were below what was observed with other catalytic systems. Noticeably, when using $\mathrm{Pd}_{1} \mathrm{Au}_{3} \mathbf{1 c}_{\mathbf{2}}$, the yield of vanillic acid increased to ca. $2 \%$. This catalyst presents the highest selectivity $(55 \%)$ of this product, probably acting somewhat differently than the other systems (see text below and Figure 10).

Concerning the Pd catalysts prepared under supercritical acetone fluidic conditions, no influence of the palladium precursor was observed since $\mathbf{2} \mathbf{a}_{\mathbf{1}}$ and $\mathbf{2} \mathbf{a}_{\mathbf{2}}$ prepared, respectively, from $\mathrm{Pd}(\text { acac })_{2}$ and $\mathrm{Pd}(\text { hfacac })_{2}$ gave approximatively the same results in term of fraction proportions with $15 \%$ of acid-insoluble phase, $50 \%$ of aqueous, and $15 \%$ of organic phases. Except a lower amount of aqueous phase, these are close to results without catalyst. Regarding the corresponding organic phase, it is noticeable that for both, ca. $2 \%$ yield of vanillin, $0.5 \%$ yield of acetovanillone, and $0.2 \%$ yield of vanillic acid were obtained. Except for vanillic acid, these yields are close to those obtained when using Pd-PVP 1a. Using formic acid during the Pd NPs synthesis under fluidic conditions did not strongly affect the results as the catalysts $\mathbf{2} \mathbf{a}_{3}$ and $\mathbf{2} \mathbf{a}_{4}$ gave approximatively the same fractionation and product yields as $\mathbf{2} \mathbf{a}_{1-2}$ and $\mathbf{2} \mathbf{b}$ did. Nevertheless, a decrease in the amount of the organic phase from 15 to $8 \%$ in favor of the acid-insoluble phase (from 15 to $25 \%$ ) was observed. This lowering of the organic phase proportion directly affected the yield of vanillin, which decreased to ca. $1.5 \%$. Unexpectedly, $2 \mathbf{a}_{2}$ prepared from $\mathrm{Pd}(\mathrm{acac})_{2}$ at longer residence time and higher temperature $\left(124 \mathrm{~s}, 300^{\circ} \mathrm{C}\right)$ gave lower lignin conversion with an increased acid-insoluble phase of $42 \%$ (vs. $15 \%$ ) and organic phase of $23 \%$ (vs. $15 \%$ ); however, mass balance overtakes $100 \%$, which is the sign of an issue in the procedure (see below). Except slightly greater yield for vanillic acid (ca. 1\%), no differences were observed in the composition of the organic phase. Finally, the use of $\mathbf{2} \mathbf{a}_{\mathbf{5}}$ and $\mathbf{2} \mathbf{a}_{\mathbf{6}}$, which were prepared from $\operatorname{Pd}(\mathrm{acac})_{2}$, for which the synthesis acetone solvent was slowly exchanged by fresh acetone and water, respectively, delivered uncommon results. Both catalysts produced 35\% of acid-insoluble phase, but the proportion of aqueous and organic phases depends strongly on the nature of the medium. While $2 \mathbf{a}_{5}$ (in fresh acetone) gave $30 \%$ of aqueous together with $45 \%$ of organic phase, $\mathbf{2} \mathbf{a}_{6}$ (in water) gave inversed proportion with $55 \%$ aqueous and $10 \%$ organic phase, corresponding more to what was observed with other Pd catalysts. The analysis of the organic phase was also very informative. If $\mathbf{2} \mathbf{a}_{\mathbf{6}}$ delivered classical aromatic compounds in relatively good yields (ca. 1.8\% for vanillin, $0.7 \%$ for acetovanillone, and $1.5 \%$ for vanillic acid, in the range as the results previously obtained), $2 \mathrm{a}_{5}$ led to low yields $(<0.5 \%)$ along with the formation on another product that was identified by GCMS to be an orthodiquinone (see Figure S5). While this compound was expected when addressing lignin depolymerization under oxidative conditions, it was never observed 
in the other experiments. Therefore, to attempt explanation, some control experiments were performed in a mixture of water and acetone (1: 0.15$)$ in the absence of catalyst and in the presence of Pd-PVP 1a. In both cases, identical orthodiquinone compound was formed in ca. $2-2.5 \%$ yield, confirming the role of acetone in this reaction. To date, no definitive reasons concerning orthodiquinone formation have been identified, but we can suggest that acetone acts as a hydrogen acceptor probably favoring deeper oxidation of some of the produced aromatic compounds to diquinone, or other providing routes to lignin depolymerization.

To summarize, the presence of a soluble catalytic system seems to not greatly influence the oxidative depolymerization of lignin. This does not mean that there is no catalytic effect since some differences are observable and deserve more attention (see following sections). From all evaluated Pd NPs, those prepared in the presence of PVP delivered the most interesting results both in terms of lignin conversion (55\%) and selectivity towards identified aromatic compounds (around 10\% of overall selectivity corresponding to $40 \%$ on organic phase basis only). This is why we were interested in immobilizing Pd NPs from this family on a stable metal oxide support $\mathrm{TiO}_{2}$ giving $\mathrm{Pd}-\mathrm{PVP} / \mathrm{TiO}_{2}$ 3a. For comparison, other $\mathrm{Pd} / \mathrm{TiO}_{2}$ catalysts $3 \mathbf{b}$ and $3 \mathbf{c}$ prepared through usual incipient wetness impregnation were also assessed.

\subsubsection{Depolymerization in the Presence of Catalyst Family 3}

When deposited on $\mathrm{TiO}_{2}$, it seems that the effect of Pd-PVP NPs decreased. Indeed, when using $\mathrm{Pd}-\mathrm{PVP} / \mathrm{TiO}_{2}$ 3a $\left(\mathrm{Pd} 1 \%{ }_{\mathrm{wt}}\right)$, more acid-insoluble phase was recovered and very close results to those achieved without any catalyst were obtained. Regarding the composition of the corresponding organic phase, it can be noticed that the catalysts did not improve the formation of vanillin. No effect of this catalyst was evidenced. Increasing the $\mathrm{Pd}$ loading in the mixture by introducing more of $3 \mathbf{a}\left(\mathrm{Pd} 10 \%{ }_{\mathrm{wt}}\right)$ presented two noticeable but reverse "apparent effects": first, by clearly increasing the proportion of acid-insoluble phase at the expense of the aqueous one, ensuring lower lignin reactivity; then, by decreasing the yield of vanillin to ca. $0.5 \%$ in favor of vanillic acid formation that raised to ca. $2.0 \%$. This resulted in higher or different reactivity of intermediates. This tendency with high Pd loading was confirmed by using Pd-PVP 1a at Pd 10\% $\%_{\text {wt }}$ (data not presented). Here, the yield of vanillin dropped to ca. 0.5\% (however, no vanillic acid was detected, probably because of analytical issues due to the relatively large amount of PVP in this case). Nevertheless, an increased amount of guaiacol was observed with a yield close to ca. 1.5\%, suggesting a decarbonylation of produced vanillin upon palladium catalysis [23], confirming that different reaction routes are possible. A possible explanation is that when 3a was introduced at $10 \%{ }_{\mathrm{wt}}$ compared to $1 \%_{\mathrm{wt}}$, a large proportion of Pd leached into the solution, thereby increasing the accessibility of soluble primary products that reacted further, leading on one side to oxidized compounds and on the other to polymeric materials that can be recovered within the acid-insoluble phase mixed with unreacted lignin matrix. Different behaviors were observed with the catalysts prepared by incipient wetness impregnation and used at a Pd loading of $1 \%{ }_{\mathrm{wt}}$. Catalysts $3 \mathbf{b}$ and $3 \mathbf{c}$ delivered results somewhat different in terms of lignin conversion when they reached $73 \%$ with $3 \mathbf{b}$ vs. $63 \%$ with $3 \mathbf{c}$. Additionally, a higher proportion of the organic phase was observed. Nevertheless, this did not reflect on target aromatic compounds formation since close yields were obtained: vanillin with ca. $2.5 \%$ yield, acetovanillone $0.7 \%$ yield, and vanillic acid $1.0-1.5 \%$ yield. Compared to 3a $10 \%$, close data were obtained in terms of reaction mixture fractionation. However, the selectivity of aromatic compounds was completely different. For 3a, the highest selectivity was observed for vanillic acid (45\%), whereas that observed for $\mathrm{Pd} / \mathrm{TiO}_{2}$ (independently of the palladium precursor) was for vanillin (50-55\%). This selectivity is similar to that obtained with Pd-PVP $1 \mathbf{a}(50 \%)$. Thus, $\mathrm{Pd} / \mathrm{TiO}_{2}$ catalysts $3 \mathbf{b}$ and $3 \mathbf{c}$ reacted similarly to Pd-PVP 1a. This contrasts with the results observed with $\mathrm{Pd}-\mathrm{PVP} / \mathrm{TiO}_{2} \mathbf{3 a}$, probably due to different palladium accessibility and/or stability. 


\subsubsection{Mechanistic Considerations}

Except in few cases, all Pd catalysts discussed above delivered similar results with the same tendency. Lignin conversion generally reached $50-80 \%$, sometimes below that obtained without catalyst $(80 \%)$. Since it appears unlikely that a catalyst inhibited lignin conversion, this observation is most likely and suggests that recombination reactions between untransformed lignin and products or lignin moieties occurred. These heavy compounds recovered in the acid-insoluble phase, leading to a lower apparent conversion. Additionally, yields of vanillin were generally not strongly affected by the nature of the catalyst and stayed in the 2.0-2.5\% range (except for Au based catalysts $1 \mathrm{c}_{1-2}, \mathrm{Pd}-\mathrm{PVP} / \mathrm{TiO}_{2}$ (with Pd $10 \%_{\mathrm{wt}} \mathbf{3 a}$ ) and catalysts prepared under supercritical fluidic conditions $\mathbf{2} \mathbf{a}_{4}$ and $2 \mathbf{a}_{5}$ giving a lower yield).

Therefore, we were interested in better understanding the potential role of $\mathrm{Pd}$ species. Accordingly, we selected Pd-PVP 1a catalyst. In a first approach, FTIR spectra of acidinsoluble phases obtained after a blank run and a catalyzed reaction, both performed under air atmosphere, were recorded and compared to that of initial Kraft lignin. Figure 11 shows that after reaction under air, and more particularly for catalyzed reaction, the intensities of the band at $1515 \mathrm{~cm}^{-1}$ (characteristic of the aromatic moieties within lignin structure) and of that at $1030 \mathrm{~cm}^{-1}$ (characteristic of ethers bonds) decreased, attesting to lignin depolymerization. In the meantime, the intensity of the band at $1650 \mathrm{~cm}^{-1}$ (characteristic of conjugated carbonyl such as benzaldehydes or quinones) increased strongly, attesting to oxidation of the lignin structure. This was much more pronounced for the catalyzed reaction.

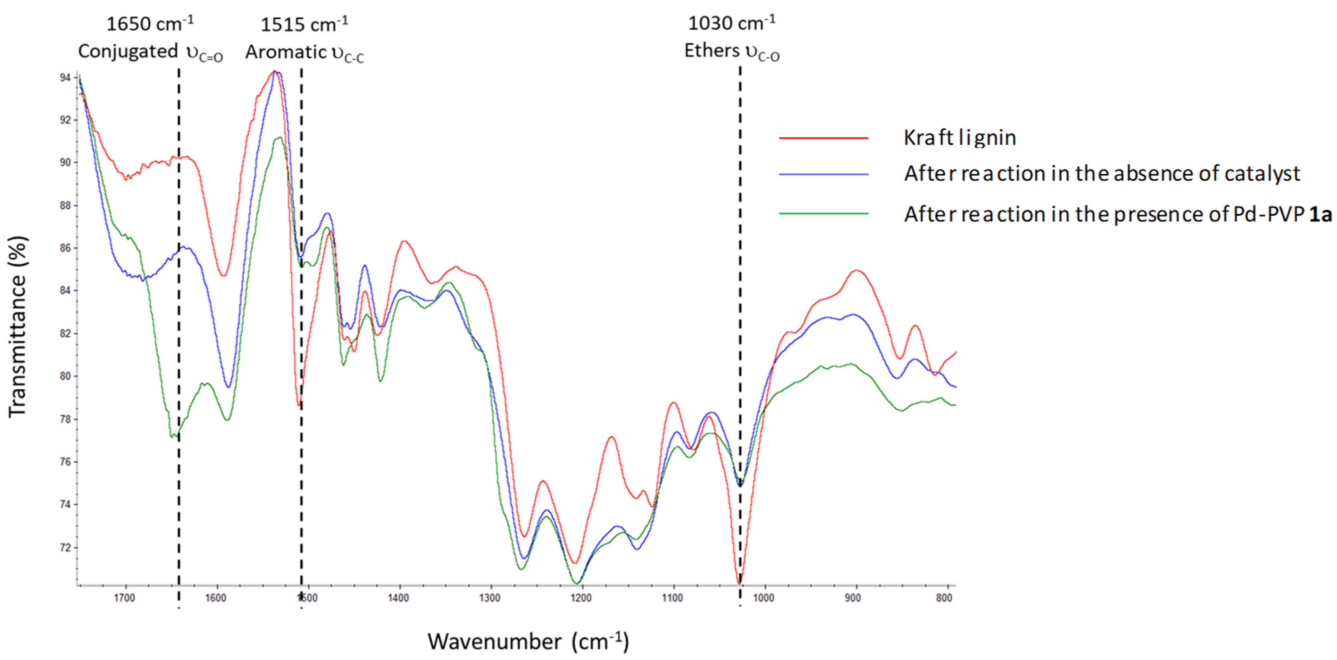

Figure 11. FTIR spectra of initial lignin and acid-insoluble phases after catalyzed and un catalyzed reactions $\left(150^{\circ} \mathrm{C}, \mathrm{P}_{\text {air }} 20\right.$ bar, $1 \mathrm{~h}, \mathrm{C}_{\text {lignin }} 5 \mathrm{~g} \mathrm{~L}^{-1}, \mathrm{C}_{\mathrm{NaOH}} 10 \mathrm{~g} \mathrm{~L}^{-1}$, and $\left.\mathrm{Pd} 10 \%{ }_{\mathrm{wt}}\right)$.

Further insights were obtained from semi-quantitative analyses of initial Kraft lignin and acid-insoluble phases by HSQC NMR spectroscopy (Table 3). Data show that the interunit structural bonds were degraded during the reaction as the $\beta-\mathrm{O}-4, \beta-\beta$, and $\beta-5$ content decreased during both reactions. Interestingly, the $\beta-\mathrm{O}-4$ content that decreased was more marked for the catalyzed reaction, suggesting that here (re)condensations occurred as generally observed for lignin, prone to condensation reaction during extraction. 
Table 3. Semi-quantitative analysis of initial Kraft lignin and acid-insoluble phase by HSQC NMR.

\begin{tabular}{cccc}
\hline Bond $^{\mathbf{1}}$ & $\begin{array}{c}\text { In Kraft } \\
\text { Lignin }\end{array}$ & $\begin{array}{c}\text { After Reaction } \\
\text { without Catalyst }\end{array}$ & $\begin{array}{c}\text { After Reaction } \\
\text { with Pd-PVP 1a }\end{array}$ \\
\hline$\beta-\mathrm{O}-4$ & 6.4 & 0.4 & 0.2 \\
$\beta-\beta$ & 2.9 & 0.3 & 0.5 \\
$\beta-5$ & 2.0 & 0.6 & 0.8 \\
\hline
\end{tabular}

${ }^{1}$ For 100 aromatic units. Calculated according to [22].

Conclusions drawn from the spectroscopic data are supported by performing reactions using an acid-insoluble phase obtained from a catalyzed reaction as a reactant. Under same conditions, this acid-insoluble phase led to further depolymerization, with conversion reaching $60 \%$, together with the formation of an organic $(13 \%)$ and aqueous $(45 \%)$ phase. However, in contrast, with Kraft lignin as reactant, the organic phase contained almost no aromatic compounds (total yield of ca. $1 \%$ with selectivity of vanillin of $40 \%$ ). This observation supports, therefore, deep lignin transformation during the oxidative depolymerization, as primarily suggested by FTIR and HSQC NMR investigations.

Spectroscopic data, together with additional catalytic reactions with acid-insoluble phase, indicate that lignin oxidation/transformation/depolymerization occurred to deliver a mixture of aromatic compounds, water-soluble products, and deeply modified non-depolymerized lignin. This occurs even in the absence of catalyst due to the basic conditions [9]. The presence of Pd species may help to perform such reactivity, especially oxidations, as proposed in Scheme 1. One possibility (Route a) involves a single-electron lignin dehydrogenative oxidation step at $\mathrm{C}_{\gamma}$ followed by base-catalyzed retro-aldol reaction giving "so-like coniferyl based-structures", delivering the expected compounds, particularly vanillin in our case [24,25]. From our previous studies [18] and literature, we can also propose that $\mathrm{Pd}$ favors the oxidation of the benzylic $\mathrm{OH}$ group at $\mathrm{C}_{\alpha}$ through the formation of $\mathrm{Pd}-\mathrm{OC}_{\alpha} \mathrm{H}$ under basic conditions, followed by hydride abstraction forming the $\mathrm{C}_{\alpha}=\mathrm{O}$ group (Route $\mathrm{b}$ ). Then, a second step, well-supported by quantum chemistry, may involve keto-enol tautomerization before $C_{\alpha}-C_{\beta}$ bond cleavage, delivering acetovanillone [26]. Finally, following the oxidation at $C_{\alpha}$ position, a base-catalyzed process taking place at the $C_{\beta}$ position can deliver corresponding vanillic acid (Route $c$ ), which is apparently the only step in which oxygen atoms from $\mathrm{O}_{2}$ are introduced in a molecular product $[27,28]$. The chemoselectivity leading (mainly) to vanillin, acetovanillone, and vanillic acid is regulated by the reactivity splitting between these routes. In our studies, except with Pd-PVP $/ \mathrm{TiO}_{2}\left(\mathrm{Pd} 10 \%{ }_{\mathrm{wt}}\right)$ 3a, $\mathrm{Pd}_{1} \mathrm{Au}_{3}-\mathrm{PVP} \mathbf{1} \mathbf{C}_{2}$, and Pd-SC-water $\mathbf{2} \mathbf{a}_{6}$, which favor vanillic acid probably due to higher oxidation activity, the selectivity was always in favor of vanillin. Acetovanillone was observed in low amount, suggesting that under our conditions tautomerism step was slower compared to $C_{\beta}$-base-catalyzed oxygen addition. 


\section{Route a}<smiles>COc1cc(C(C)(O)C(CO)O[AlH2])ccc1O</smiles><smiles>COc1cc(C(O)C(C=O)O[AlH2])ccc1[O-]</smiles><smiles>COc1cc(C=O)ccc1O</smiles>

\section{Route b}<smiles>COc1cc(C(C)(O)C(CO)O[AlH2])ccc1O</smiles><smiles>COc1cc(C(=O)C(CO)O[AlH2])ccc1O</smiles><smiles>COc1cc(/C(O)=C(/CO)O[AlH2])ccc1O</smiles>

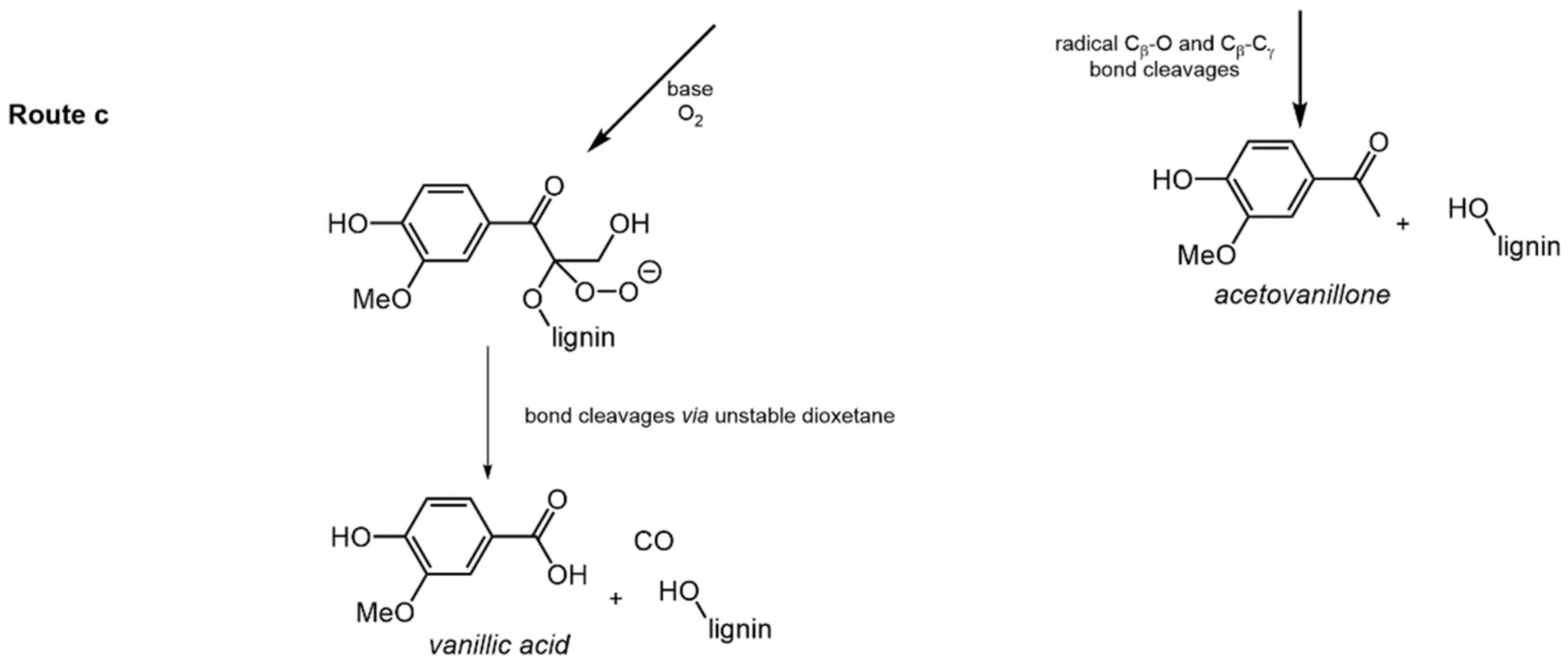

Scheme 1. Proposed mechanisms for reactions occurring during the Pd-catalyzed lignin depolymerization under oxidative conditions based on [24-28].

\section{Materials and Methods}

\subsection{General Information}

All chemicals and solvents were obtained from Sigma-Aldrich (Saint-Quentin-Fallavier, France), Merck Chemicals (Fontenay-sous-Bois, France), or Alfa Aesar (Kandel, Germany) in their highest purity and used as received. $\mathrm{TiO}_{2}$ P25 was obtained from Evonik (Evonik Industries AG, Essen, Germany) and used without pre-treatment.

\subsection{Procedures for Synthesis of Catalysts}

Catalyst 1a was prepared as previously reported [18]. In short, $\mathrm{Na}_{2} \mathrm{PdCl}_{4}\left(7.05 \times 10^{-5} \mathrm{~mol}\right.$ of $\mathrm{Pd})$ was dissolved in water $(8 \mathrm{~mL})$ at room temperature. A solution of PVP K30 (10 $\left.\mathrm{mol}_{\text {equiv. }} / \mathrm{Pd}\right)$ in water $(8 \mathrm{~mL})$ was added slowly. The mixture was stirred for $30 \mathrm{~min}$. A solution of $\mathrm{NaBH}_{4}$ $\left(2.5\right.$ mol $\left._{\text {equiv. }} / \mathrm{Pd}\right)$ in water was added quickly, giving a black suspension of $\mathrm{Pd}(0)$ nanoparticles $\left(3.5 \mathrm{mmol} \mathrm{L}{ }^{-1}\right)$. The suspension was stable with time and could be used after $24 \mathrm{~h}$ as catalytic system. Catalysts $\mathbf{1} \mathbf{b}$ and $\mathbf{1} \mathbf{c}_{\mathbf{1 - 2}}$ were synthesized following the same procedure using $\mathrm{HAuCl}_{4}$ as precursor.

Catalysts $\mathbf{2} \mathbf{a}_{\mathbf{1}-\mathbf{6}}$ were prepared from $\mathrm{Pd}(\mathrm{acac})_{2}$ and catalyst $\mathbf{2} \mathbf{b}$ from $\mathrm{Pd}(\mathrm{hfacac})_{2}$ in supercritical fluid flow conditions using acetone as solvent [29]. The synthesis system consists of injecting the acetone solution $\left(200 \mathrm{~mL}, 10 \mathrm{mmol} \mathrm{L}{ }^{-1}\right.$ of $\mathrm{Pd}, 5 \mathrm{mmol} \mathrm{L}^{-1}$ for 2a4) using a HPLC pump into a reactor $\left(1 / 8^{\prime \prime}\right.$ tubing, $\left.540 \mathrm{~cm}, 7.17 \mathrm{~cm}^{3}\right)$ heated at $300{ }^{\circ} \mathrm{C}$. 
An outlet connecting to an ice bath collects in flow post-synthesis Pd solutions. For $\mathbf{2} \mathbf{a}_{3}$ and $\mathbf{2} \mathbf{a}_{4}$, formic acid (100 $\mathrm{mmol} \mathrm{L}^{-1}$ and $20 \mathrm{mmol} \mathrm{L}^{-1}$, respectively) was added to the initial acetone solution. After collection of the reaction mixture, the reactor was rinsed by flushing several times fresh acetone with a sudden change of the pressure (200 to $1 \mathrm{bar}$ ). With Pd (hfacac) 2 , a significant number of particles were also collected during the rinsing steps. Materials $\mathbf{2} \mathbf{a}_{\mathbf{1}-\mathbf{4}}$ and $\mathbf{2} \mathbf{b}$ were obtained as powder after synthesis acetone evaporation and drying. Dissolution in water in the presence of PVP formed the catalytic system (see below). Materials $\mathbf{2} \mathbf{a}_{5}$ and $\mathbf{2} \mathbf{a}_{6}$ were obtained in synthesis acetone. Acetone was displaced slowly by fresh acetone or water, delivering solutions serving as catalytic systems.

Catalyst $3 \mathbf{a}$ was prepared as previously reported by impregnating $\mathrm{TiO}_{2}$ by an excess of solution 1a [18]. Before impregnation, the $\mathrm{pH}$ of solution was buffered to 2 by addition of $\mathrm{HCl} 10 \%$. The suspension was stirred for $1 \mathrm{~h}$ at room temperature. After filtration, the resulting solid was dried, calcined $\left(450{ }^{\circ} \mathrm{C}\right.$, air flow, $\left.3 \mathrm{~h}\right)$, reduced $\left(300{ }^{\circ} \mathrm{C}, \mathrm{H}_{2}\right.$ flow, $\left.3 \mathrm{~h}\right)$, and passivated $\left(25^{\circ} \mathrm{C}, 1 \% \mathrm{O}_{2} / \mathrm{N}_{2}\right.$ flow, $\left.30 \mathrm{~min}\right)$ to give a solid with $2.2 \%{ }_{\mathrm{wt}}$ of $\mathrm{Pd}\left(57 \mathrm{~m}^{2} \mathrm{~g}^{-1}\right)$. The same procedure was applied for the preparation of catalysts $3 \mathbf{b}$ and $3 \mathbf{c}$ by classical incipient wetness using a solution of $\mathrm{Na}_{2} \mathrm{PdCl}_{4}$ and $\left(\mathrm{NH}_{3}\right)_{2} \mathrm{PdCl}_{4}$, giving solids whose characteristics are reported in Table 3.

\subsection{Procedures for Characterization of Catalysts}

Transition Electron Microscopy pictures were obtained on a JEOL 2010 apparatus with LaB6 tip (JEOL Ltd. Tokyo, Japan), an instrumental magnification of 50,000 $\times$ to $100,000 \times$, and an acceleration voltage of $200 \mathrm{kV}$. The microscope was equipped with an EDX link ISIS analyser from Oxford Instruments (Oxford Instruments France, Gometzla-ville, France). Samples were prepared depending on the synthesis mode, either as dispersion of the solid in ethanol or directly as water drop, by deposition on standard holey carbon-covered copper TEM grids. The size distributions were determined via manual analysis of enlarged pictures by measuring ca. 200 particles to obtain a statistical size distribution and a mean diameter.

$\mathrm{Pd}$ and Au content were determined by ICP-OES (Activa Horiba Jobin-Yvon, Longjumeau, France). The solid was dissolved with $\mathrm{HCl} / \mathrm{HNO}_{3}$, followed by complete water evaporation before further digesting the residue in conc. $\mathrm{HCl}$ at $250-300{ }^{\circ} \mathrm{C}$.

Specific surface area was determined from BET equations. Analysis was carried out on an ASAP 2020 of micromeritics (Micromeritics France SARL, Mérignac, France), equipped with two pressure sensors using $\mathrm{N}_{2}$ at a temperature of $-196^{\circ} \mathrm{C}$. Samples were previously desorbed for $3 \mathrm{~h}$ at $300{ }^{\circ} \mathrm{C}$ under high vacuum.

\subsection{Procedures for Lignin Reactivity}

Reactions of lignin were carried in a $300 \mathrm{~mL}$ closed reactor equipped with a mechanical agitation and connected to an air reserve to maintain a constant pressure. The reactor containing $150 \mathrm{~mL}$ of a $\mathrm{NaOH}_{\text {aqu }}$. solution $\left(\mathrm{C}_{\text {lignin }} 5 \mathrm{~g} \mathrm{~L}^{-1}, \mathrm{C}_{\mathrm{NaOH}} 10 \mathrm{~g} \mathrm{~L}^{-1}\right.$, measured $\mathrm{pH}$ 13.5) was flushed then times with $\mathrm{N}_{2}$ and then heated to $150^{\circ} \mathrm{C}$ under $500 \mathrm{rpm}$ agitation. The reactor was then pressurized under air (20 bars) at $1500 \mathrm{rpm}$ agitation, defining the starting time of the reaction. When a catalyst was present, the solution $\mathbf{1 a - c _ { 1 - 2 }}$ or $\mathbf{2} \mathbf{a}_{5-6}$ was used directly as catalytic system. Materials $\mathbf{2} \mathbf{a}_{1-4}$ and $\mathbf{2 b}$ were dissolved in water in the presence of PVP ( $\left.10 \mathrm{~mol}_{\text {equiv. }} / \mathrm{Pd}\right)$ using ultra-sounds, producing a catalytic system that was added to the lignin solution. Solids $\mathbf{3 b}-\mathbf{c}$ were introduced as prepared in the lignin solution. In all cases, the stoichiometry was adapted to introduce the same amount of $\mathrm{Pd}$ in the reactor. After a given time, the reaction was stopped by cooling the reactor in an ice bath. After solid catalyst separation $(3 \mathbf{b}-\mathbf{c})$ by filtration, the reaction mixture was acidified by adding $\mathrm{HCl} 10 \%(8 \mathrm{~mL})$ to $\mathrm{pH} 1$ to precipitate the non-liquefied lignin and dissolve Pd species of Families 1 and 2. This solid was recovered by centrifugation (4000 rpm, $10 \mathrm{~min}$ ), washed with $\mathrm{HCl} 10 \%(10 \mathrm{~mL})$ then water $(10 \mathrm{~mL})$, and dried under dynamic vacuum $\left(5 \times 10^{-5} \mathrm{mbar}\right)$, leading the acid-insoluble phase. The solution was washed with $\mathrm{CH}_{2} \mathrm{Cl}_{2}(3 \times 100 \mathrm{~mL})$ to extract the aromatic products left after evaporation 
under vacuum $\left(5 \times 10^{-3}\right.$ mbar $)$ in the "organic phase". The remaining aqueous phase (containing salts $(\mathrm{NaCl})$ and water-soluble organic compounds) was dried under vacuum and washed with THF ( $5 \mathrm{~mL}$ several times until decolouration). All THF fractions were collected and evaporated under vacuum $\left(5 \times 10^{-3}\right.$ mbar $)$ to obtain the "aqueous phase".

\subsection{Procedures for Analysis of Reaction Mixture}

The number of various types of products (solid, aromatic organics, and water-soluble organics) was expressed as proportions of the acid-insoluble, organic, and aqueous phases, respectively, from the initial lignin, according to the following equation:

$$
\text { Fraction }(\%)=\frac{m_{\text {dried phase }}}{m_{\text {lignin introduced }}} \times 100
$$

The conversion of the lignin was expressed as:

$$
\text { Conversion }(\%)=100-F_{\text {acid insoluble phase }}
$$

The composition of the organic phase (aromatic organics) was determined using gas chromatography. Analyses were performed on a Shimadzu GC-2010 chromatograph (Shimadzu Europa GmbH, Duisburg, Germany) equipped with a FID detector, a AOC20i+ autosampler and a Macherey-Nagel Optima 5 MS Accent column (5\% diphenyl-95\% dimethylpolysiloxane, $30 \mathrm{~m}, 0.25 \mathrm{~mm}, 0.25 \mu \mathrm{m}$ ) (Macherey-Nagel SAS, Hoerdt, France). Hydrogen was used as carrier gas, and the program was $60{ }^{\circ} \mathrm{C}$ for $2 \mathrm{~h}$, up to $150{ }^{\circ} \mathrm{C}$ $\left(30{ }^{\circ} \mathrm{C} \mathrm{min}-1\right)$, up to $200{ }^{\circ} \mathrm{C}\left(2{ }^{\circ} \mathrm{C} \mathrm{min}^{-1}\right)$, and up to $260{ }^{\circ} \mathrm{C}\left(10^{\circ} \mathrm{C} \mathrm{min}-1\right)$, for $2 \mathrm{~min}$. Yields were determined by calibration of commercial samples with decane as external standard.

Elemental analyses were performed at the Institut des Sciences Analytiques of CNRS (ISA, Villeurbanne, France). Oxygen content was measured after pyrolysis and quantification of $\mathrm{CO}$ by a specific IR detector. Carbon, hydrogen, nitrogen, and sulfur contents were measured after total combustion of the sample and quantification of $\mathrm{CO}_{2}, \mathrm{H}_{2} \mathrm{O}, \mathrm{N}_{2}$, and $\mathrm{SO}_{2}$ by a thermal conductivity detector.

Infrared spectra (FTIR) were recorded on a Thermo Fisher Scientific Nicolet iS5 spectrometer (Thermo Fisher Scientific, Illkirch, France) in the range $4000-525 \mathrm{~cm}^{-1}$ in attenuated total reflectance (ATR) mode.

NMR spectra were acquired on a Bruker AVANCE III $400 \mathrm{MHz}$ (Bruker Corporation, Billerica, MA, USA) equipped with a BBFO probe ( $\mathrm{Z}$ gradient). Chemical shifts were given relatively to the deuterated solvents in case of ${ }^{13} \mathrm{C} \mathrm{NMR}\left(\mathrm{CDCl}_{3} \delta=77.0 \mathrm{ppm}\right.$, $\left.\left(\mathrm{CD}_{3}\right)_{2} \mathrm{SO} \delta=39.7 \mathrm{ppm}\right)$, or to the residual protic solvent for ${ }^{1} \mathrm{H} \mathrm{NMR}\left(\mathrm{CDCl}_{3} \delta=7.26 \mathrm{ppm}\right.$, $\left.\left(\mathrm{CD}_{3}\right)_{2} \mathrm{SO} \delta=2.50 \mathrm{ppm}\right)$. For ${ }^{31} \mathrm{P} \mathrm{NMR}$, the chemical shifts were that of the products of the reaction of 2-chloro-4,4,5,5-tetramethyl-1,3,2-dioxaphospholane (TMDP) with hydroxyl groups of lignin in pyridine- $\mathrm{CDCl}_{3}$ solvent (relative to $\mathrm{H}_{3} \mathrm{PO}_{4} 80 \%$ ). Data are reported as follows: chemical shift, multiplicity $(\mathrm{s}=$ singlet, $\mathrm{d}=$ doublet, $\mathrm{t}=$ triplet, $\mathrm{q}=$ quartet, and $\mathrm{m}=$ multiplet), coupling constants $(\mathrm{J} \mathrm{Hz})$, integration, and assignments. For ${ }^{1} \mathrm{H}$ NMR analysis, around $8 \mathrm{mg}$ of sample was dissolved in $0.6 \mathrm{~mL}$ of a solution containing TKS (concentration: $0.04 \mathrm{mg}_{\text {ssolution }}{ }^{-1}$ ) in $\left(\mathrm{CD}_{3}\right)_{2} \mathrm{SO}$. For ${ }^{13} \mathrm{C}$ and HSQC NMR analyses, $50 \mathrm{mg}$ of sample was dissolved in $600 \mathrm{mg}$ of $\left(\mathrm{CD}_{3}\right)_{2} \mathrm{SO}$. For ${ }^{13} \mathrm{C}$ experiments, $0.1 \mathrm{~mL}$ of a solution containing tetramethylthiourea $\left(40 \mathrm{mg} \mathrm{g}_{\text {solution }}{ }^{-1}\right)$ and $\mathrm{Fe}(\mathrm{acac})_{3}\left(4 \mathrm{mg} \mathrm{g}_{\text {solution }}{ }^{-1}\right)$ was added to the sample. Acquisitions were performed at $50{ }^{\circ} \mathrm{C}$ overnight $\left({ }^{13} \mathrm{C} 11,000\right.$ scans; HSQC 48 scans). The characterization of hydroxyl groups of lignin was realized using the method based on ${ }^{31} \mathrm{P}$ NMR after derivatization with TMDP enabling quantification of different $\mathrm{OH}$ groups (phenol, aliphatic, and carboxylic) using cyclohexanol as internal standard. For that, an accurate mass of the sample $(30 \mathrm{mg})$ was dissolved in $0.5 \mathrm{~mL}$ of a solution of cyclohexanol $\left(3.95 \mathrm{mg} \mathrm{g}_{\text {solution }}{ }^{-1}\right)$ in a combination of pyridine and DMF (1/1) before addition of $\mathrm{CDCl}_{3}(200 \mathrm{mg})$ and TMDP $(100 \mathrm{mg})$. 


\section{Conclusions}

Palladium-based catalysts were evaluated for depolymerizing Kraft lignin under aqueous basic condition in a close reactor under air (oxidative conditions). The catalysts were prepared following several routes, leading to several types of systems. The routes included the formation of Pd (and Au) PVP-stabilized nanoparticles in water, the preparation of $\mathrm{Pd}$ nanoparticles in the absence of an external stabilizer through an innovative methodology in supercritical acetone flow conditions, and the preparation of Pd-nanoparticles supported on $\mathrm{TiO}_{2}$ from different precursors. All catalytic systems were characterized by dedicated techniques. Data showed that, except for the materials prepared under supercritical fluidic conditions, small nanoparticles could be obtained, in the range of 1.5-7.0 nm. When prepared under supercritical fluidic conditions, Pd nanoparticles showed greater average diameter, between 10 and $12 \mathrm{~nm}$, but it was demonstrated that variation in some reaction parameters ( $\mathrm{Pd}$ precursor, residence time, temperature, co-reagent as formic acid) allowed one to somewhat control the morphology. When analyzed in solution at the reactor outlet, usually well-defined particles were observed, with morphologies varying from icosahedrons, to triangular bipyramids, to rods or bars. However, after drying or acetone displacing, as required to perform the catalytic tests, morphologies were not further observed since generally aggregates were obtained. TEM showed that, depending on the synthetic conditions, particles with an average size of 9-12 $\mathrm{nm}$ could still be obtained.

These catalysts of different types were evaluated in Kraft lignin oxidative depolymerization under aqueous basic conditions. Generally, all evaluated catalysts, except few exceptions, delivered very close results: lignin apparent conversion reached $50-70 \%$, with vanillin being the main aromatic compound produced in yields varying from ca. 1.5 to $2.5 \%$. These results fall in the range of what can be found in the literature. Unexpectedly, compared to the absence of catalyst, lignin conversion was not improved, but the acidinsoluble phase was generally increased from $20 \%$ to $50 \%$, without affecting strongly the yields of aromatic products. This leads to the hypothesis that recondensation reactions, less favored in the absence of catalyst, occurred through Pd-catalyzed reactions. Spectroscopic investigations by FTIR and HSQC NMR on both initial Kraft lignin and the acid-insoluble phase strongly support this possibility.

Nevertheless, we demonstrated in some cases that by varying the type of the catalyst, noticeably different selectivity can be achieved regarding produced aromatic compounds. While generally, with PVP-stabilized Pd and Au nanoparticles in water, vanillin was the main aromatic product, selectivities can favor vanillic acid when using Pd nanoparticles immobilized on $\mathrm{TiO}_{2}$ or PVP-stabilized $\mathrm{Au}_{3} \mathrm{Pd}_{1}$. Here, with a close lignin conversion, selectivity of vanillic acid increased to $60 \%$ vs. $15-30 \%$. In addition, we observed that when acetone was present in the reaction mixture (from the catalysts obtained under the fluidic approach), an orthodiquinone formed with a significant yield. The mechanism for its formation has not been elucidated so far, but it seems reasonable to propose that acetone, in the presence of $\mathrm{Pd}$ species, induced another route for lignin oxidation involving its hydrogen acceptor properties.

In general, deeper insights to establish structure/reactivity relationships when using noble metal catalysts (here $\mathrm{Pd}, \mathrm{Au}$ ) for depolymerizing lignin to functional aromatic compounds are still needed. From this study, as far as the formation of vanillin from Kraft lignin is concerned, the best catalysts were PVP-stabilized Pd nanoparticles in water, or $\mathrm{Pd} / \mathrm{TiO}_{2}$. For the formation of vanillic acid, $\mathrm{Pd}-\mathrm{PVP} / \mathrm{TiO}_{2}$ or PVP-stabilized $\mathrm{Au}_{3} \mathrm{Pd}_{1}$ nanoparticles in water are preferred. In addition, the recovery of catalysts, either for recycling or reuse, needs to be envisioned. Here, supported metal nanoparticles present a clear advantage. In light of the data provided by these results, work is ongoing with the aim of achieving better control of the morphology, stability, and recovery potential of noble metal-based catalysts. In addition, the possibility of using metals with fewer oxidant behaviors, such as cupper, is being investigated. This is to be linked to the selectivity of the depolymerization of lignin, particularly by attempting to prevent recondensation reactions that certainly occur and limit good yields of desired oxygenated aromatic products. 
Supplementary Materials: The following are available online at https:/ / www.mdpi.com/article/10 .3390 / catal11111311/s1, Scanning electron microscopy pictures (Table S1); X-ray diffraction spectra (Figure S1); Plane indexing (Figure S2); ${ }^{13} \mathrm{C}$ NMR spectra of Kraft lignin (Figure S3); ${ }^{31} \mathrm{P}$ NMR spectra of Kraft lignin after reaction with TMDP (Figure S4); C content of Kraft lignin (Table S2); mass spectra of orthodiquinone (Figure S5).

Author Contributions: Conceptualization, D.B., L.D. and C.A.; methodology, D.B., L.D. and F.R.; investigation, D.B., F.G., Y.X., L.B. and G.A.; data curation, D.B., L.D., F.R., C.A. and P.F.; writingoriginal draft preparation, D.B. and L.D.; writing-review and editing, L.D., F.R. and C.A.; visualization, D.B., L.D. and R.P.; supervision, F.R. and L.D.; project administration, L.D. and F.R.; funding acquisition, L.D. All authors have read and agreed to the published version of the manuscript.

Funding: This research was funded by the French National Research Agency (NANOTRAP N ${ }^{\circ}$ ANR-17-CE07-0027-01).

Data Availability Statement: The data presented in this study are available on request from the corresponding author.

Acknowledgments: The authors thank C. Lorentz (IRCELYON) for help with NMR analyses, and F. Bourgain, M. Dupanloup, and M. Ben-Hadj (IRCELYON) for technical assistance. The authors gratefully acknowledge the National Agency of Research (NANOTRAP N ${ }^{\circ}$ ANR-17-CE07-0027-01) for funding. D.B. thanks the National Agency of Research (NANOTRAP N ${ }^{\circ}$ ANR-17-CE07-0027-01) for PhD grant. The authors thank AXELERA, cluster for the chemical and environmental sectors, for support.

Conflicts of Interest: The authors declare no conflict of interest. The funder had no role in the design of the study; in the collection, analyses, or interpretation of data; in the writing of the manuscript; or in the decision to publish the results.

\section{References}

1. Liu, X.; Bouxin, F.P.; Fan, J.; Budarin, V.L.; Hu, C.; Clark, J.H. Recent Advances in the Catalytic Depolymerization of Lignin towards Phenolic Chemicals: A Review. ChemSusChem 2020, 13, 4296-4317. [CrossRef]

2. Ha, J.-M.; Hwang, K.-R.; Kim, Y.-M.; Jae, J.; Kim, K.H.; Lee, H.W.; Kim, J.-Y.; Park, Y.-K. Recent progress in the thermal and catalytic conversion of lignin. Renew. Sustain. Energy Rev. 2019, 111, 422-441. [CrossRef]

3. Chio, C.; Sain, M.; Qin, W. Lignin utilization: A review of lignin depolymerization from various aspects. Renew. Sustain. Energy Rev. 2019, 107, 232-249. [CrossRef]

4. Wang, H.; Pu, Y.; Ragauskas, A.; Yang, B. From lignin to valuable products-strategies, challenges, and prospects. Bioresour. Technol. 2019, 271, 449-461. [CrossRef] [PubMed]

5. Schutyser, W.; Renders, T.; Van den Bosch, S.; Koelewijn, S.F.; Beckham, G.T.; Sels, B.F. Chemicals from lignin: Interplay of lignocellulose fractionation, depoly-merisation, and upgrading. Chem. Soc. Rev. 2018, 47, 852-908. [CrossRef]

6. Deuss, P.J.; Barta, K. From models to lignin: Transition metal catalysis for selective bond cleavage reactions. Coord. Chem. Rev. 2016, 306, 510-532. [CrossRef]

7. Rinaldi, R.; Jastrzebski, R.; Clough, M.T.; Ralph, J.; Kennema, M.; Bruijnincx, P.C.A.; Weckhuysen, B.M. Paving the Way for Lignin Valorisation: Recent Advances in Bioengineering, Biorefining and Catalysis. Angew. Chem. Int. Ed. 2016, 55, 8164-8215. [CrossRef] [PubMed]

8. Hanson, S.K.; Baker, R.T. Knocking on Wood: Base Metal Complexes as Catalysts for Selective Oxidation of Lignin Models and Extracts. Accounts Chem. Res. 2015, 48, 2037-2048. [CrossRef] [PubMed]

9. Cabral Almada, C.; Kazachenko, A.; Fongarland, P.; Perez, D.D.S.; Kuznetsov, B.N.; Djakovitch, L. Oxidative depolymerization of lignins for producing aromatics: Variation of botanical origin and extraction methods. Biomass-Convers. Biorefinery 2020, 1-14. [CrossRef]

10. Ma, R.; Guo, M.; Zhang, X. Recent advances in oxidative valorization of lignin. Catal. Today 2018, 302, 50-60. [CrossRef]

11. Schutyser, W.; Kruger, J.S.; Robinson, A.M.; Katahira, R.; Brandner, D.G.; Cleveland, N.S.; Mittal, A.; Peterson, D.J.; Meilan, R.; Román-Leshkov, Y.; et al. Revisiting alkaline aerobic lignin oxidation. Green Chem. 2018, 20, 3828-3844. [CrossRef]

12. Chatel, G.; Rogers, R.D. Review: Oxidation of Lignin Using Ionic Liquids-An Innovative Strategy To Produce Renewable Chemicals. ACS Sustain. Chem. Eng. 2013, 2, 322-339. [CrossRef]

13. Lange, H.; Decina, S.; Crestini, C. Oxidative up-grade of lignin-recent routes reviewed. Eur. Polym. J. 2013, 49, 1151-1173. [CrossRef]

14. Bjørsvik, H.-R.; Minisci, F. Fine Chemicals from Lignosulfonates. 1. Synthesis of Vanillin by Oxidation of Lignosulfonates. Org. Process. Res. Dev. 1999, 3, 330-340. [CrossRef]

15. Bourbiaux, D.; Pu, J.; Rataboul, F.; Djakovitch, L.; Geantet, C.; Laurenti, D. Reductive or oxidative catalytic lignin depolymerization: An overview of recent advances. Catal. Today 2021, 373, 24-37. [CrossRef] 
16. Cabral Almada, C.; Kazachenko, A.; Fongarland, P.; Perez, D.D.S.; Kuznetsov, B.; Djakovitch, L. Supported-Metal Catalysts in Upgrading Lignin to Aromatics by Oxidative Depolymerization. Catalysts 2021, 11, 467. [CrossRef]

17. Kuznetsov, B.; Sharypov, V.; Baryshnikov, S.; Miroshnikova, A.; Taran, O.; Yakovlev, V.; Lavrenov, A.; Djakovitch, L. Catalytic hydrogenolysis of native and organosolv lignins of aspen wood to liquid products in supercritical ethanol medium. Catal. Today 2020, 379, 114-123. [CrossRef]

18. Bourbiaux, D.; Mangematin, S.; Djakovitch, L.; Rataboul, F. Selective Aerobic Oxidation of Benzyl Alcohols with Palladium(0) Nanoparticles Suspension in Water. Catal. Lett. 2021, 151, 3239-3249. [CrossRef]

19. Deng, W.; Zhang, H.; Wu, X.; Li, R.; Zhang, Q.; Wang, Y. Oxidative conversion of lignin and lignin model compounds catalyzed by CeO2-supported Pd nanoparticles. Green Chem. 2015, 17, 5009-5018. [CrossRef]

20. Sales, F.G.; Maranhão, L.C.A.; Lima Filho, N.M.; Abreu, C.A.M. Kinetic evaluation and modeling of lignin catalytic wet oxi-dation to selective production of aromatic aldehydes. Ind. Eng. Chem. Res. 2006, 45, 6627-6631. [CrossRef]

21. Bertaud, F.; Guillemain, A.; Tapin-Lingua, S.; Molina-Boisseau, S.; Petit-Conil, M. Softwood Kraft lignin isolation from black liquor: From laboratory to pilot-scale production. Revue ATIP 2015, 69, 6-9.

22. Wen, J.-L.; Sun, S.-L.; Xue, B.-L.; Sun, R.-C. Recent Advances in Characterization of Lignin Polymer by Solution-State Nuclear Magnetic Resonance (NMR) Methodology. Materials 2013, 6, 359-391. [CrossRef]

23. Modak, A.; Deb, A.; Patra, T.; Rana, S.; Maity, S.; Maiti, D. A general and efficient aldehyde decarbonylation reaction by using a palladium catalyst. Chem. Commun. 2012, 48, 4253-4255. [CrossRef]

24. Tarabanko, V.E.; Tarabanko, N. Catalytic Oxidation of Lignins into the Aromatic Aldehydes: General Process Trends and Development Prospects. Int. J. Mol. Sci. 2017, 18, 2421. [CrossRef] [PubMed]

25. Tarabanko, V.E.; Fomova, N.A.; Kuznetsov, B.N.; Ivanchenko, N.M.; Kudryashev, A.V. On the mechanism of vanillin formation in the catalytic oxidation of lignin with oxygen. React. Kinet. Catal. Lett. 1995, 55, 161-170. [CrossRef]

26. de Andrade, A.M.; Srifa, P.; Broqvist, P.; Hermansson, K. Lignin intermediates on palladium: Insights into keto-enol tautomerization from theoretical modelling. ChemSusChem 2020, 13, 6574-6581. [CrossRef] [PubMed]

27. Sun, C.; Zheng, L.; Xu, W.; Dushkin, A.V.; Su, W. Mechanochemical cleavage of lignin models and lignin via oxidation and a subsequent base-catalyzed strategy. Green Chem. 2020, 22, 3489-3494. [CrossRef]

28. Lee, T.W.; Yang, J.W. Transition-metal-free conversion of lignin model compounds to high-value aromatics: Scope and chemoselectivity. Green Chem. 2018, 20, 3761-3771. [CrossRef]

29. Xu, Y.; Musumeci, V.; Aymonier, C. Chemistry in supercritical fluids for the synthesis of metal nanomaterials. React. Chem. Eng. 2019, 4, 2030-2054. [CrossRef] 